\title{
Oogenesis and lipid metabolism in the deep-sea sponge Phakellia ventilabrum: an histological, lipidomic and transcriptomic approach
}

\section{Vasiliki Koutsouveli ( $\nabla$ vassiakouts88@gmail.com )}

GEOMAR: Helmholtz-Zentrum fur Ozeanforschung Kiel https://orcid.org/0000-0001-9117-0598

\section{David Balgoma}

Uppsala University: Uppsala Universitet

\section{Antonia Checa}

Karolinska Institute: Karolinska Institutet

\section{Mikael Hedeland}

Uppsala University: Uppsala Universitet

\section{Ana Riesgo}

Museo Nacional de Ciencias Naturales

\section{Paco Cárdenas}

Uppsala University: Uppsala Universitet

\section{Research article}

Keywords: deep-sea, sponges, P.ventilabrum, reproduction, lipidomics, triacylglycerides, transcriptomics

Posted Date: June 16th, 2021

DOI: https://doi.org/10.21203/rs.3.rs-608731/v1

License: (c) (i) This work is licensed under a Creative Commons Attribution 4.0 International License. Read Full License 


\section{Abstract}

Background Sponges contain an astounding diversity of lipids which serve in several biological functions, including yolk formation in their oocytes and the embryos. On animal reproduction, lipids constitute one of the main energy storage forms for the adult and the offspring. The study of lipid metabolism during reproduction can provide information on foodweb dynamics and energetic needs of the populations in their habitats, however, there are no studies focusing on the lipid metabolism of sponges during seasonal reproduction. The deep-sea sponge Phakellia ventilabrum (Demospongiae, Bubarida) is a key species of North-Atlantic sponge grounds, but its reproductive biology is not known. In this study, we used histological sections, lipidome profiling (UHPLC-MS), and transcriptomic analysis (RNA-seq) with goal to i. assess the reproductive strategy and seasonality of this species, ii. examine the relative changes in the lipidome signal, and the gene expression patterns (RNA-seq) of enzymes participating in lipid metabolism in female specimens during gametogenesis.

Results $P$. ventilabrum is an oviparous and most certainly gonochoristic species, reproducing in May and September in the different studied areas. Half of specimens were reproducing, generating two to five oocytes per $\mathrm{mm}^{2}$. Oocytes accumulated both protein and lipid droplets. As oogenesis progressed, the signal of most of the unsaturated and monounsaturated triacylglycerides increased, as well as of few other phospholipids. Most of the other lipids and especially those with $>3$ unsaturations showed a decrease in signal during the oocyte maturation. In parallel, we detected upregulated genes in female tissues related to triacylglyceride biosynthesis and others related to fatty acid beta-oxidation.

Conclusions Triacylglycerides are probably the main type of lipid forming the yolk since this lipid category has the most marked changes, while some other phospholipids may also have a role in oogenesis. In parallel, other lipid categories were oxidized, leading to fatty acid beta-oxidation to cover the energy requirements of female individuals during oogenesis. Variations in the signal of most lipids between the different locations and months suggest that sponges, apart from their own mechanisms of lipid biosynthesis, exploit the food availability in their surroundings to cover the energetic demands in their physiological processes.

\section{Background}

Lipids are particularly diverse in marine organisms $(1,2)$. They provide the most important source of energy $(3)$ and are indicators of the ecosystems' health (4-7). Lipids are necessary nutrients (8-11), but are also the main elements of cell membranes and play critical roles in several physiological functions, e.g. buoyancy $(12,13)$, tissue growth, immunity, and wound healing $(2,3,14)$.

Lipids are also used as energy storage (15) in the eggs during gamete formation and embryogenesis of many marine organisms, including zooplankton, crustacea, cnidaria and fish (16-19). There is therefore a direct link between reproduction and lipid metabolism in animals (20). Lipid metabolism, nutrient transport and yolk accumulation (stage of vitellogenesis) are crucial processes during gametogenesis/ embryogenesis because they determine the production of a successful gamete and propagule (21-24), and in parallel they can affect the survival of the adult during reproduction. For this reason, many species synchronize their gametogenesis with periods of high food availability in the environment in order to withstand the high energetic demands (25-27). Due to its importance, the relationship of lipid metabolism with seasonal environmental changes and the reproductive period has been studied in several marine organisms across their development, addressing questions such as: which types of lipids are preferred for the yolk formation; what is the source of these lipids (e.g. to understand the food web dynamics); and what is the timing of lipid synthesis, lipid accumulation and lipid consumption $(2,11,16,18,19,28-33)$.

Sponges (phylum Porifera), especially within the class Demospongiae (34-40), produce an exceptional diversity of lipids. As in other animals, lipids are of particular importance in sponges because they participate in several biological processes like cellular signal transduction and cell aggregation $(41,42)$, adaptation to shifting environmental conditions (temperature, 
oxygen, osmolarity, diet, pressure), defence from predators, and antioxidant activity (38,43-46). Sponge lipids have also been studied for their potential pharmaceutical applications, e.g. several demosponge fatty acids exhibit antimalarial, antimycobacterial and antifungal activity $(1,47)$ and many glycolipids have anti-inflammatory, anticomplement, antitumoral, and immunomodulatory properties (48-51). In regard to their role in reproduction, yolk of lipid origin is also one of the main components, together with protein platelets, of oocytes and embryos of sponges (52). Sponge yolk has either a homogeneous (53-55) or heterogeneous structure with a mix of lipids and proteins in the same yolk platelet (5660). But notably, in some demosponges, lipid droplets are the only nutrients accumulated within the oocytes (55). Yolk is formed by i) autosynthesis, in which the egg itself produces the nutrients, and ii) heterosynthesis through phagocytosis of yolk precursors, nutrients and bacteria either provided from accessory cells or taken from the mesohyl of the sponge (58,60-62). Currently, the type of sponge yolk is only assessed by electron microscopy observations in which the lipid and protein yolk can be largely recognized by their different electron dense nature: proteins are more electron dense showing crystal structure and lipids appear lighter and relatively more homogeneous (63).

Almost all sponges have lecithotrophic larvae $(64,65)$ and only a handful of deep-sea species are known to have direct development (from embryo directly to young sponge without the larval phase) (66-68). With the lack of a planktotrophic phase, all of the nutrients needed for the next developmental stages, until settlement and metamorphosis into a sessile adult sponge, are accumulated in the egg during gametogenesis in the oviparous species or during embryogenesis in the viviparous species. Consequently, the quality and quantity of the yolk is crucial to provide the propagule with all the necessary energy.

Few studies have investigated the variations of sponge lipid metabolism with respect to seasonality. Koopmans et al. (69) studied fatty acid (FA) composition in North-East Atlantic/Meditarranean Sea demosponge species of the genera Haliclona, Halichondria and Aplysina and found a strong correlation between the FA composition in the surrounding dissolved organic matter and the sponge FAs during nutrient blooms in spring-summer. On the other hand, Lüskow et al. (70) measuring the lipid content as a fraction of sponge dry weight, found that it remained invariable throughout the year, without being affected by seasonal planktonic blooms or periods of starvation. However, none of these studies linked directly these variations with reproduction. Two other studies, using obsolete methods and rough estimates, have linked the seasonality and nutrient blooms with the physiological status of sponges: Reiswig (71) quantified the nutritional resources within the sponge tissue and found a direct link to growth and reproduction in the Jamaican population of Mycale sp., and Elvin (72) quantified the tissue growth and reproductive output with respect to various abiotic factors (temperature, light, salinity and nutrient abundance) in Haliclona (Reniera) cf. cinerea (H. permollis in the publication). Finally, Elvin (73) studied the direct relationship of lipid content and reproductive investment in $H$. (R.) cf. cinerea, finding that both protein and lipid levels increased in female individuals just before the onset of gametogenesis. However, the nature of the lipids used in reproduction i) for energetic demands and ii) for the formation of yolk platelets is still almost completely unknown in sponges. Presently, a single study has investigated the expression levels of lysophospholipids in the homoscleromorph viviparous sponge Oscarella tuberculata (74) in response to seasonality and reproduction, and found that their levels increased towards the end of the reproductive cycle: during embryogenesis and larval development (75). Understanding the lipid level fluctuations during the reproductive period is very important from an ecological point of view, in order to understand nutrient availability, food-web dynamics, and energy requirements of sponge populations. Lipid content dynamics can also inform about the ability to survive and reproduce in case of habitat disturbance, including unbalance in lipid sources due to contamination of the habitat, changes in nutrient blooms, sediment resuspension blocking the filtering system and no access to nutrient uptake and lipid storage. Additionally, such studies are pivotal from an evolutionary point of view, to understand the origin and evolution of yolk formation and lipid composition in Metazoa.

Sponges of the genus Phakellia (order Bubarida), including $P$. ventilabrum, are key species in boreal deep-sea sponge grounds of the North Atlantic (76-78). These sponge habitats have an immense ecological importance for the ecosystem 
due to the crucial role sponges play in biogeochemical cycles (79-84), and the biodiversity of associated fauna $(76,78)$. Despite being a very common species, from the British Isles to the coasts of Norway and Sweden, the reproduction of this species has never been investigated. Interestingly, some of its FAs have been previously identified with GC-MS (36,39). In the present study, we chose to investigate the reproductive strategy of the boreal deep-sea demosponge, Phakellia ventilabrum (85) with histological observations (light and electron microscopy). Furthermore, we compared the lipid profile (UHPLC-HRMS) and the expression levels (RNA-seq) of genes related to lipid metabolism in reproductive female $v s$ nonreproductive specimens of this species. By doing so, we aimed to determine i) the types of lipids used for yolk formation ii) the molecular routes involved in the production of these lipids and iii) the energetic demands during gametogenesis in this species. Therefore, information on the reproduction of Phakellia species will significantly improve our understanding of sponge ground habitats and in the long run contribute to their conservation.

\section{Results}

\section{Reproductive biology}

\subsection{Reproductive season}

Reproductive activity was found in specimens collected both in March (Swedish coast) and September (Norwegian coast) (Table 1). P. ventilabrum is an oviparous species, as no further developmental stage, e.g. embryos, was observed within the tissue. Although no male individuals were found in none of the locations, P. ventilabrum is expected to be gonochoristic since all species of Bubarida follow this strategy, but we cannot exclude the possibility of successive hermaphroditism. At the population level, $50 \%$ of the collected specimens (two out of four) were female in the Swedish coast in March, while $66.6 \%$ (six out of nine) were female in the population of the Norwegian coast, in September (Table 1). There was relatively asynchronous development of the gametes within the populations, with some individuals having previtellogenic oocytes, while others had oocytes in a more advanced developmental stage. Asynchronous oocyte development was also observed within the same individual in a few cases. The density of oocytes was around 2 to 5 oocytes per $\mathrm{mm}^{2}$ sponge tissue (Table 1).

Table 1: Information on the sampling characteristics and the reproductive status of Phakellia ventilabrum specimens studied. The asterisks signal the samples that were also used for the transcriptomic analysis 


\begin{tabular}{|c|c|c|c|c|c|c|c|}
\hline $\begin{array}{l}\text { sampling } \\
\text { location }\end{array}$ & $\begin{array}{l}\text { sampling } \\
\text { date }\end{array}$ & specimens & status & code & $\begin{array}{c}\text { number of } \\
\text { oocytes } / \mathrm{mm}^{2}\end{array}$ & $\begin{array}{l}\text { diameter } \\
\text { of } \\
\text { oocytes } \\
(\mu \mathrm{m})\end{array}$ & $\begin{array}{c}\text { area } \\
\text { occupied } \\
\text { by } \\
\text { oocytes / } \\
\text { pm2 }\end{array}$ \\
\hline $\begin{array}{l}\text { Skorpeodden, } \\
\text { Korsfjord, } \\
\text { Norway (59 } \\
58.8790^{\prime} \mathrm{N}, 05^{\circ} \\
\left.22.4371^{\prime} \mathrm{E}\right)\end{array}$ & 8-Sep-16 & $\begin{array}{c}\text { Specimen } \\
1\end{array}$ & Oogenesis & $\begin{array}{c}\text { pre- } \\
\text { vitellogenic } \\
\text { (PV) }\end{array}$ & 5 & $25 \pm 3$ & 0.004415 \\
\hline $\begin{array}{c}\text { Langenuen, } \\
\text { Norway } \\
\left(59^{\circ}\right. \\
58.8790^{\prime} \mathrm{N}, 05^{\circ} \\
\left.22.4371^{\prime} \mathrm{E}\right) \\
\end{array}$ & 9-Sep-16 & $\begin{array}{c}\text { Specimen } \\
2\end{array}$ & Oogenesis & $\begin{array}{c}\text { pre- } \\
\text { vitellogenic } \\
\text { (PV) }\end{array}$ & 2 & $17 \pm 7$ & 0.003803 \\
\hline $\begin{array}{c}\text { Langenuen, } \\
\text { Norway }\end{array}$ & 9-Sep-16 & $\begin{array}{c}\text { Specimen } \\
3\end{array}$ & Oogenesis & $\begin{array}{l}\text { pre- } \\
\text { vitellogenic } \\
\text { (PV) }\end{array}$ & 3 & $23 \pm 2$ & 0.007567 \\
\hline $\begin{array}{l}\text { Skorpeodden, } \\
\text { Korsfjord, } \\
\text { Norway }\end{array}$ & 8-Sep-16 & $\begin{array}{c}\text { Specimen } \\
4^{*}\end{array}$ & Oogenesis & $\begin{array}{c}\text { vitellogenic_I } \\
\text { (Vi_I) }\end{array}$ & 3 & $40 \pm 1$ & 0.047715 \\
\hline $\begin{array}{c}\text { Langenuen, } \\
\text { Norway }\end{array}$ & 9-Sep-16 & $\begin{array}{c}\text { Specimen } \\
5\end{array}$ & Oogenesis & $\begin{array}{c}\text { vitellogenic_II } \\
\text { (Vi_II) }\end{array}$ & 2 & $71 \pm 14$ & 0.075556 \\
\hline $\begin{array}{c}\text { Langenuen, } \\
\text { Norway }\end{array}$ & 9-Sep-16 & $\begin{array}{c}\text { Specimen } \\
6^{*}\end{array}$ & Oogenesis & $\begin{array}{c}\text { vitellogenic_II } \\
\text { (Vi_II) }\end{array}$ & 5 & $62 \pm 2$ & 0.126028 \\
\hline $\begin{array}{l}\text { Skorpeodden, } \\
\text { Korsfjord, } \\
\text { Norway }\end{array}$ & 8-Sep-16 & $\begin{array}{c}\text { Specimen } \\
7\end{array}$ & $\begin{array}{l}\text { non- } \\
\text { reproductive }\end{array}$ & - & & - & - \\
\hline $\begin{array}{l}\text { Skorpeodden, } \\
\text { Korsfjord, } \\
\text { Norway }\end{array}$ & 8-Sep-16 & $\begin{array}{l}\text { Specimen } \\
8^{*}\end{array}$ & $\begin{array}{l}\text { non- } \\
\text { reproductive }\end{array}$ & - & & - & - \\
\hline $\begin{array}{l}\text { Skorpeodden, } \\
\text { Korsfjord, } \\
\text { Norway }\end{array}$ & 8-Sep-16 & $\begin{array}{l}\text { Specimen } \\
9^{*}\end{array}$ & $\begin{array}{l}\text { non- } \\
\text { reproductive }\end{array}$ & - & & - & - \\
\hline $\begin{array}{l}\text { Krugglöbranten, } \\
\text { Sweden } \\
\left(58^{\circ} 53.10^{\prime} \mathrm{N},\right. \\
\left.11^{\circ} 06.04^{\prime} \mathrm{E}\right)\end{array}$ & $\begin{array}{c}\text { 28-Mar- } \\
19\end{array}$ & $\begin{array}{l}\text { Specimen } \\
10\end{array}$ & Oogenesis & $\begin{array}{c}\text { vitellogenic_II } \\
\text { (Vi_II) }\end{array}$ & 2 & $57 \pm 14$ & 0.039863 \\
\hline $\begin{array}{c}\text { Krugglöbranten, } \\
\text { Sweden }\end{array}$ & $\begin{array}{c}\text { 29-Mar- } \\
19\end{array}$ & $\begin{array}{c}\text { Specimen } \\
11\end{array}$ & Oogenesis & $\begin{array}{c}\text { vitellogenic_II } \\
\text { (Vi_II) }\end{array}$ & 2 & $53 \pm 11$ & 0.028747 \\
\hline $\begin{array}{c}\text { Krugglöbranten, } \\
\text { Sweden }\end{array}$ & $\begin{array}{c}\text { 28-Mar- } \\
19\end{array}$ & $\begin{array}{l}\text { Specimen } \\
12\end{array}$ & $\begin{array}{c}\text { non- } \\
\text { reproductive }\end{array}$ & 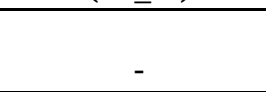 & & - & - \\
\hline $\begin{array}{c}\text { Krugglöbranten, } \\
\text { Sweden }\end{array}$ & $\begin{array}{c}\text { 29-Mar- } \\
19\end{array}$ & $\begin{array}{c}\text { Specimen } \\
13\end{array}$ & $\begin{array}{c}\text { non- } \\
\text { reproductive }\end{array}$ & - & & - & - \\
\hline
\end{tabular}

\subsection{Ultrastructure of oocytes}

The previtellogenic oocytes of $P$. ventilabrum, with an already well-formed nucleolated nucleus, had an average size of 20 $\pm 5 \mu \mathrm{m}$ at the beginning of their formation (Figs. 1A, 2A). During their maturation phase (vitellogenic stage I, Vi_I), oocytes increased in size to $\sim 40 \mu \mathrm{m}$, (Figs. 1B, 2A), and at a later vitellogenic stage (Vi_II), oocytes reached $80 \mu \mathrm{m}$ (Figs. 1C, 2A). We expect that the maximum size of oocytes would not surpass $100 \mu \mathrm{m}$ as Vi_ll oocytes were already close to the canals, ready to be released (Fig. 1D). During the maturation phase, nutrients of lipidic or heterogeneous form started to accumulate in the ooplasm (Figs. 1E, 2B). Nurse cells were present in the proximity of the oocytes, since their early formation, and they contained lipidic yolk, indicating that they probably provide the oocyte with nutrients (Fig. 1E). All three different types of yolk: lipidic, proteinaceous and heterogenous (mix of lipid and protein) yolk, were present in both Vi_I 
and Vi_ll oocytes (Figs. 1E-H, 2B). Between $22.5 \%$ and $29.5 \%$ of the oocyte area was filled by yolk in the Vi_I stage and Vi_ll stage respectively (Fig. 2B). Heterogenous yolk was the most abundant type of yolk observed in the oocytes (Figs. $1 \mathrm{E}-\mathrm{H}, 2 \mathrm{~B})$. At the Vi_I stage, big droplets of heterogeneous yolk were mainly observed (Fig. 1E-F) with only a few homogeneous lipid and protein droplets (Figs. 1E-F, 2B). From Vi_I to Vi_Il, all three types of yolk increased both in number and size (Fig. 2B). In some Vi_Il oocytes, protein platelets were more abundant (Fig. 1G), while in some others, lipid droplets were equally abundant to the other two types of yolk (Fig. 1H). Altogether, lipid and protein yolk were formed in similar amounts while heterogenous yolk occupied twice the area of the ooplasm, compared to the other two (Fig. 2B). Although vertical transmission of associated microsymbionts was not observed in this species, a phagocytosis of a bacterium by the oocyte was observed in a single instance (Fig. 1G, insert). From the histological observations, it is clear that $P$. ventilabrum is a Low Microbial Abundant (LMA) species, as almost no bacteria were observed in the mesohyl.

\section{Lipidomic analysis}

To characterize the changes of the lipidome in relation to the reproductive status, we analysed the samples by semitargeted mass spectrometry lipidomics with relative quantification. In total, we detected 532 different lipids in the extracts of $P$. ventilabrum with a remarkable variety of lipids (Additional file 1: Table S1). The main lipid categories were: 96 free fatty acids (FFAs) (Additional file 1: Table S1), 61 phosphatidylcholines (PC) (Additional file 1: Table S1) and 155 triacylglycerides, (TGs) (Additional file 1: Table S1); and finally, 26 sphingolipids and glycosphingolipids (Additional file 1: S1). In most of the above lipid categories, the highest number of lipids detected with our analysis was unsaturated fatty acids (UFA), and most particularly polyunsaturated fatty acids (PUFA) (Fig. 3), which also had the highest signals (Fig. 3). Exceptions were the phosphatidylglycerols (PGs), lysophosphatidylcholines (LPCs) and sphingolipids for which the number of SFA or MFA detected was higher than PUFA and had higher signal detections (Fig. 3).

We also identified and determined 62 oxylipins by absolute quantification, derived from PUFAs such as arachidonic acid (AA), linoleic acid (LA), a-linolenic acid (ALA), eicosapentaenoic acid (EPA), and docosahexaenoic acid (DHA). Among others, we detected oxylipins derived from $A A: P_{2} D_{2}$ (prostaglandin $D_{2}$ ), $P_{2} E_{2}$ (prostaglandin $E_{2}$ ), $P G F_{2 a}$ (prostaglandin $F_{2}$ ), hydroxyeicosatetraenoic acids (HETEs), hydroxyeicosatrienoic acids (HETrEs), dihydroxyeicosatetraenoic acids (DiHETEs), dihydroxyeicosatrienoic acids (DiHETrEs), hydroxyheptadecatrienoic acid (12-HHTrE), oxoeicosatetraenoic acids (KETEs), epoxyeicosatrienoic acids (EpETrEs), lipoxin $\mathrm{A}_{4}\left(\mathrm{LXA}_{4}\right)$; oxylipins derived from LA: hydroxy-octadecadienoic acid (HODE), oxo-octadecadienoic acid (KODE); derived from EPA: prostaglandin $E_{3}\left(P_{G} E_{3}\right)$, prostaglandin $F_{3 a}\left(P G F_{3 a}\right)$, hydroxyeicosapentaenoic acids (HEPEs), epoxyeicosatetraenoic acids (EpETE), LXA (lipoxin $A_{5}$ ); derived from DHA: hydroxydocosahexaenoic acids (HDoHE), epoxydocosapentaenoic acids (EpDPEs); derived from ALA: hydroxyoctadecatrienoic acids (HOTrEs) (Additional file 1: Table S1).

\subsection{Lipid signal variations in different locations/months}

The main variation in the lipidome among the specimens was due to the different sampling locations/months or both, independently of the reproductive status (Fig. 4A). Among the different locations, the total signal of almost all the main lipid categories studied was higher in samples collected in Kosterfjord (Sweden) in March than in Korsfjord (Norway) in September (Fig. 4B; Additional file 1: Table S1). Especially the lipid categories of PC, PG, PE, LPE, and PUFA_FFA were two to seven times higher (Fig. 4B; Additional file 1: Table S1). Studying the variation of the signal within each lipid category, significant differences were observed in several monounsaturated fatty acids (MFA) and polyunsaturated fatty acids (PUFA) (Additional file 2: SF1), PGs (Additional file 2: SF1) and also in PCs with PUFA (Additional file 2: SF1). Regarding the TG group, only three TGs (TG(50:3), TG(62:3), TG(69:3)) varied significantly (Additional file 2: SF1) with location/month. PEs with 2 or 3 unsaturations were also significantly different in the two locations/months (Additional file 2: SF1). In almost all the lipid categories, the PUFA lipids had the most varied signal between the locations/ months (PUFAFFA; PUFA-PC; PUFA-TG; PUFA-PE) (Fig. 4B; Additional file 2: SF1). In some cases, there was absence of some lipids in almost all the individuals of one or the other location/month. For instance, FFAs: FA(24:2)_2; FA(25:2)_2; FA(26:2)_3; PCs: 
PC(35:1)_1; PC(37:1)_1; PC(34:2)_1; PC(34:3)_1; PC(36:3)_4; PC(38:3)_1; LPCs: LPC(20:0)_2, LPC(21:0)_1 and LPE(17:0)_1; and TGs: TG(52:2); TG(63:2), TG(65:2)) were absent in individuals from Kosterfjord, March, while several PEs: $P E(0-$ 49:3)/PE(P-49:2); PE(0-51:3)/PE(P-51:2); PE(0-51:4)/PE(P-51:3); PE(0-52:3)/PE(P-52:2) were absent in almost all the individuals from Korsfjord, September (Additional file 1: Table S1).

\subsection{Lipid signal variations dependent on the reproductive statuses}

To analyse the variation in the lipidome regarding the reproduction, we correlated the variation in the lipid signal to the area of the sponge tissue occupied by oocytes, focusing mainly on the larger lipid categories detected in our analysis. Female specimens with an increasing area occupied by oocytes are considered those with more mature oocytes because during maturation process, the oocytes get larger (see paragraph 1.2) (Table 1). The sponge tissue of nonreproductive specimens (NR) did not have any oocytes. In regard to the general signal fluctuation of each lipid category, the majority of lipids indicated a tendency to decrease their signal with the oocyte maturation (increasing area occupied by oocytes), with the exception of the TGs, which in their majority increased their signal with oocyte maturation (Figs. 5, 6; Additional file 3 : Table S2).

Specific observations were made on the lipids of each lipid category, based on their number of carbons and unsaturation. Particularly regarding the FFA, a higher percentage of SFAs (57\%) and MFAs (56\%) decreased their signal (vs $28 \%$ and $37 \%$ increased respectively) with oocyte maturation (the area occupied by oocytes increased) (Fig. 5), while an almost equal percentage of PUFAs had their signal decreased (39\%) or increased (47\%) (Fig. 5). Specifically, PUFA FFA with 2 or 3 unsaturations showed an increase while those FFA with a higher number of unsaturations $(4,5$, or 6$)$ tended to decrease their signal in relation to the increasing area of the oocytes (Fig. 6A). As for the LPCs, the most of SFA (60\%), MFA (53\%) and PUFA (60\%) decreased their signal while a $33 \%, 33 \%$, and $40 \%$ of them showed a higher signal towards the females with mature oocytes respectively (Figs. 4, 5B). Regarding PCs, only 10-16 \% of the different lipid categories had a higher signal in females with mature oocytes, while the 47-70\% decreased their signal with the highest negative trend among PUFA PCs with 4 - 6 unsaturations (Figs. 5, 6C; Additional file 3: Table S2). On the contrary, a larger percentage of SFA (42\%) and MFA (65\%) TGs had an increasing signal in females during oocyte maturation (vs $25 \%$ and $17 \%$ respectively with decreasing signal), while most of the PUFA TGs (56\%) showed to decrease their signal (Figs. 5, 6D). Only the $22 \%$ of the PUFA TGs increased their signal during oocyte maturation (Figs. 5, 6D) and within this 22\%, most of them were of 2 and fewer of 3 unsaturations (Fig. 6D; Additional file 3: Table S2). Regarding other lipids, PEs (their methylated counterparts PMeE and PDMeE), LPE, PGs, and LPGs followed the same trend to decrease in reproductive sponges (Additional file 3: Table S2; Additional file 4, Fig. S1). Finally, ether glycerophospholipids with PUFAs, such as etherPCs, etherPEs, etherPMeEs, etherPDMeEs also behaved similarly (Additional file 3: Table S2, Additional file 4, Fig. S1).

Sphingolipids presented different sphingoid bases, from sphingosine or sphinganine, to ceramides and glucosylceramides (respectively, Cer(d) and Glc-Cer(d)). From phytosphingosine, also ceramides and glucosylceramides were detected (respectively, Cer(d) and Glc-Cer(d)). The different sphingolipids did not present a clear change with oocyte maturation (Figs. 5, 6E), but they rather decreased their signal.

Finally, we studied the regulation of different oxylipins along oocyte maturation (Figs. 5, 6F). They presented a general decreasing trend. Remarkably, HEPEs and HDoHEs presented the highest decreasing trend and only the PGE 2 and $\mathrm{PGF}_{2}$, as also the 12-HHTrE and 5(6)-EpETrE increased their signal with oocyte maturation (Fig. 6F).

\section{Lipid signal variations in different locations/months}

The main variation in the lipidome among the specimens was due to the different sampling locations/months or both, independently of the reproductive status (Fig. 4A). Among the different locations, the total signal of almost all the main lipid categories studied was higher in samples collected in Kosterfjord (Sweden) in March than in Korsfjord (Norway) in September (Fig. 4B; Additional file 1: Table S1). Especially the lipid categories of PC, PG, PE, LPE, and PUFA_FFA were two 
to seven times higher (Fig. 4B; Additional file 1: Table S1). Studying the variation of the signal within each lipid category, significant differences were observed in several monounsaturated fatty acids (MFA) and polyunsaturated fatty acids (PUFA) (Additional file 2: SF1), PGs (Additional file 2: SF1) and also in PCs with PUFA (Additional file 2: SF1). Regarding the TG group, only three TGs (TG(50:3), TG(62:3), TG(69:3)) varied significantly (Additional file 2: SF1) with location/month. PEs with 2 or 3 unsaturations were also significantly different in the two locations/months (Additional file 2: SF1). In almost all the lipid categories, the PUFA lipids had the most varied signal between the locations/ months (PUFAFFA; PUFA-PC; PUFA-TG; PUFA-PE) (Fig. 4B; Additional file 2: SF1). In some cases, there was absence of some lipids in almost all the individuals of one or the other location/month. For instance, FFAs: FA(24:2)_2; FA(25:2)_2; FA(26:2)_3; PCs: PC(35:1)_1; PC(37:1)_1; PC(34:2)_1; PC(34:3)_1; PC(36:3)_4; PC(38:3)_1; LPCs: LPC(20:0)_2, LPC(21:0)_1 and LPE(17:0)_1; and TGs: TG(52:2); TG(63:2), TG(65:2)) were absent in individuals from Kosterfjord, March, while several PEs: PE(O49:3)/PE(P-49:2); $\mathrm{PE}(0-51: 3) / \mathrm{PE}(\mathrm{P}-51: 2) ; \mathrm{PE}(0-51: 4) / \mathrm{PE}(\mathrm{P}-51: 3) ; \mathrm{PE}(0-52: 3) / \mathrm{PE}(\mathrm{P}-52: 2)$ were absent in almost all the individuals from Korsfjord, September (Additional file 1: Table S1).

\subsection{Lipid signal variations dependent on the reproductive statuses}

To analyse the variation in the lipidome regarding the reproduction, we correlated the variation in the lipid signal to the area of the sponge tissue occupied by oocytes, focusing mainly on the larger lipid categories detected in our analysis. Female specimens with an increasing area occupied by oocytes are considered those with more mature oocytes because during maturation process, the oocytes get larger (see paragraph 1.2) (Table 1). The sponge tissue of nonreproductive specimens (NR) did not have any oocytes. In regard to the general signal fluctuation of each lipid category, the majority of lipids indicated a tendency to decrease their signal with the oocyte maturation (increasing area occupied by oocytes), with the exception of the TGs, which in their majority increased their signal with oocyte maturation (Figs. 5, 6; Additional file 3 : Table S2).

Specific observations were made on the lipids of each lipid category, based on their number of carbons and unsaturation. Particularly regarding the FFA, a higher percentage of SFAs (57\%) and MFAs (56\%) decreased their signal (vs $28 \%$ and $37 \%$ increased respectively) with oocyte maturation (the area occupied by oocytes increased) (Fig. 5), while an almost equal percentage of PUFAs had their signal decreased (39\%) or increased (47\%) (Fig. 5). Specifically, PUFA FFA with 2 or 3 unsaturations showed an increase while those FFA with a higher number of unsaturations $(4,5$, or 6$)$ tended to decrease their signal in relation to the increasing area of the oocytes (Fig. 6A). As for the LPCs, the most of SFA (60\%), MFA (53\%) and PUFA (60\%) decreased their signal while a $33 \%, 33 \%$, and $40 \%$ of them showed a higher signal towards the females with mature oocytes respectively (Figs. 4, 5B). Regarding PCs, only 10-16 \% of the different lipid categories had a higher signal in females with mature oocytes, while the 47-70\% decreased their signal with the highest negative trend among PUFA PCs with 4 - 6 unsaturations (Figs. 5, 6C; Additional file 3: Table S2). On the contrary, a larger percentage of SFA (42\%) and MFA (65\%) TGs had an increasing signal in females during oocyte maturation (vs $25 \%$ and $17 \%$ respectively with decreasing signal), while most of the PUFA TGs (56\%) showed to decrease their signal (Figs. 5, 6D). Only the $22 \%$ of the PUFA TGs increased their signal during oocyte maturation (Figs. 5, 6D) and within this 22\%, most of them were of 2 and fewer of 3 unsaturations (Fig. 6D; Additional file 3: Table S2). Regarding other lipids, PEs (their methylated counterparts PMeE and PDMeE), LPE, PGs, and LPGs followed the same trend to decrease in reproductive sponges (Additional file 3: Table S2; Additional file 4, Fig. S1). Finally, ether glycerophospholipids with PUFAs, such as etherPCs, etherPEs, etherPMeEs, etherPDMeEs also behaved similarly (Additional file 3: Table S2, Additional file 4, Fig. S1).

Sphingolipids presented different sphingoid bases, from sphingosine or sphinganine, to ceramides and glucosylceramides (respectively, Cer(d) and Glc-Cer(d)). From phytosphingosine, also ceramides and glucosylceramides were detected (respectively, Cer(d) and Glc-Cer(d)). The different sphingolipids did not present a clear change with oocyte maturation (Figs. 5, 6E), but they rather decreased their signal. 
Finally, we studied the regulation of different oxylipins along oocyte maturation (Figs. 5, 6F). They presented a general decreasing trend. Remarkably, HEPEs and HDoHEs presented the highest decreasing trend and only the PGE 2 and $\mathrm{PGF}_{2}$, as also the 12-HHTrE and 5(6)-EpETrE increased their signal with oocyte maturation (Fig. 6F).

\section{Discussion}

In our study we found that the sponge species $P$. ventilabrum was gonochoric and most possibly oviparous, reproducing in spring and end of summer/ autumn in Kosterfjord and Korsfjord respectively. Our comparative lipidomic and transcriptomic analysis shows that during oogenesis and at the stage of yolk formation, the signal of most TGs increases and their possible de novo lipogenesis occurs while in parallel the signal of other lipid categories decreases with their possible beta-oxidation. Our results suggest that TGs might be the main component of the energy stock in the female gametes while other lipids undergo degradation to generate energy for the adult during this energetically high consuming process.

\section{Seasonality and reproductive strategy of $P$ ventilabrum}

In both locations and sampling times, individuals with mature, vitellogenic oocytes were found among the collected specimens (Table 1), indicating either that this species may have two annual reproductive cycles (one from February to May and another one from August to October) or that this species has different reproductive cycles among the different locations, probably triggered by local abiotic factors. Even though it is difficult to conclude on the reproductive period of $P$. ventilabrum, having samples only from an extremely restricted period of time, we expect that its reproductive cycle coincides with that of other demosponge species, like Geodia spp. which are present at the same locations $(86,87)$. Spetland and collaborators (86) found two reproductive cycles for some populations of Geodia barretti (88) at Kosterfjord, with one spawning season to be estimated in late spring (May/June) and the other in October. In both sampling locations of our study, there is a spring planktonic bloom during March - April, and a smaller one during August - September (8991). Previous studies have shown that the seasonal reproductive cycles of deep-sea sponges from the orders Polymastiida and Tetractinellida and the deep-sea coral Lophelia pertusa (92) in boreo-arctic North-Atlantic were correlated to seasonal nutrient blooms $(11,86,93)$. Previously, it has been stated that the seasonal primary production and the subsequent nutrients reaching the seafloor, influence the reproductive cycle of organisms $(94,95)$ in deep-sea habitats where the rest of abiotic conditions are constant along the year.

$P$. ventilabrum is an oviparous species with potentially lecithotrophic larvae (as other members of closely related orders) or even direct development, so all the nutrients are accumulated in the egg during vitellogenesis. Here we observed that the oocyte maturation phase in specimens of $P$. ventilabrum, during which yolk accumulation occurs, was synchronized with the predictable increase of energy stocks in the surroundings, as noted previously for other deep-sea organisms (96).

The yolk within the oocytes of $P$. ventilabrun was heterogeneous, composed of proteins and lipids. We do not have any information on reproductive strategies of other sponge species from the same genus, with the exception of a study on Phakellia hirondellei Topsent, 1980 (97). They briefly reported only protein platelets within the oocyte of $P$. hirondellei. The closest phylogenetically sponge species being studied more extensively is Raspaciona aculeata of the order of Axinellida, (98) with heterogeneous yolk, mainly of protein origin described in the oocytes. Protein synthesis has proven more costly energetically in cold waters than in temperate environments for adult isopods (99), but the cost for protein synthesis was very low during the early developmental stages of the Antarctic sea urchin Sterechinus neumayeri (100). There is no study calculating the metabolic cost of protein and lipid synthesis in sponges from cold habitats. However, lipid was the only type of yolk present in the Antarctic sponge Mycale acerata, and was considered an adaptation to cold environments since its Caribbean counterpart M. laevis had mainly heterogeneous yolk (55). Similarly, Geodia spp. from the boreo-arctic deepsea contained much more lipid yolk (87) than Geodia cydonium from shallow temperate waters (101). From the above we 
could hypothesize that the yolk origin in $P$. ventilabrum is governed both by phylogenetic constrains and adaptation to its boreal water environment, revealing higher amounts of lipid yolk than its counterparts.

\section{Lipidome and gene expression variations during oogenesis}

Reproduction is energetically a very costly process, and many changes on lipid metabolism have been observed in marine invertebrates during this period of time, with some lipids to increase and others to degrade $(20,102)$. Indeed, some lipid categories constitute the nutrients for the future embryo (lipid droplets formed during phase of vitellogenesis) and they increase in female individuals suggesting their de novo synthesis and other lipids provide energy resources for the adult, so they are catabolized during gamete formation (oocyte growth, differentiation, nutrient formation and nutrient transport). Our lipidomic analysis revealed that sponges remodel their lipidome during oogenesis following a tendency to i) increase TGs with SFAs and MFAs, ii) decrease glycerophospholipids, iii) decrease PUFAs with a high number of unsaturations and iv) increase the beta-oxidation of FFAs.

Almost half of the detected SFA and MFA TGs showed a tendency to increase their signal from NR towards the females with mature oocytes (Figs. 5, 6D) suggesting that this type of lipid could be the main component of yolk in this species. TGs store much more energy (10 times higher/gram) than any other type of lipids and carbohydrates (103), and are the most compacted form of energy storage (104). In marine organisms, TGs, together with wax esters (WE) and sterols (ST), are the main forms of energy storage $(10,28,105)$ and are very common in deep-sea fauna, including sponges (2). While cnidaria prefer WE/ST as storage lipids, deep-sea sponges use both TGs and WE/ST to store their energy (2). Interestingly, in the gametes and reproductive organs, so of terrestrial (106-109) as also of many marine invertebrates $(18,110-113)$, TGs together with phospholipids (PLs) also provide the most common source of energy storage. This supports our hypothesis for the role of TGs in yolk storage in the oocytes of $P$. ventilabrum.

SFA and MFA TGs, e.g. TG(49:0), TG(58:0), TG(52:0), TG(54:0), TG(50:1), TG(48:1), TG(52:1) which had the highest tendency to increase their signal along oogenesis, are associated with de novo lipogenesis (114). Furthermore, we observed a decrease of several of the free fatty acids that constitute these TGs, such as FA(16:0) or FA(18:0) (Fig. 6A), which could be explained by a more extensive incorporation of these fatty acids into TGs. Most of the genes regulating the enzymes of the TG biosynthetic pathway (most of which also participate in PL biosynthetic pathway) $(115,116)$ were overexpressed in females with vitellogenic oocytes (either Vi_I or Vi_II or both), confirming the occurrence of de novo lipogenesis in female individuals, likely engaged in yolk formation (Fig. 8; Additional file 10: Table S7; Additional file 11: Table S8). The gene regulating the penultimate enzyme in the TG biosynthesis: diacylglycerol acyltransferase (dgat) was the only one not significantly overexpressed, but still with a tendency of increased expression in females with Vi_I oocytes (Fig. 8A, C). GO enriched categories, KEGG pathways and other upregulated genes related to the long chain FAs and elongation of FAs were also overexpressed in females (Fig. 8B; Additional file 8: Table S5, Additional file 11: Table S8; Additional file 12: Fig. S2), possibly also related to TG biosynthesis as TGs contain particularly long-chain FAs (117). In general, SFA and MFA FAs can generate a higher equivalent of ATP (118) and this might suggest that the enrichment of TGs with less unsaturated fatty acids is associated with a higher energy accumulation during reproduction.

In our analysis, even though the majority of PLs were decreasing their signal as oogenesis progressed, a 20\% of the PLs exhibited an increased signal (Figs. 5, 6, Additional file 3: Table S2), indicating that they could also have a role in yolk formation /oogenesis but in a more selective way than TGs. Possibly the different lipids participate in the formation of different fractions (homogeneous lipid platelets/ heterogeneous lipid-protein platelets) of the lipid yolk in sponges as it has been previously reported on the lizard Zootoca vivipara (named as Lacerta vivipara, in the publication) (119). Another potential role of PLs could be the formation of lipoproteins for TG transport. TGs have a hydrophobic nature and they are transported extracellularly or intracellularly in animals in the form of lipoproteins (120). Even though there are no studies discussing the presence and role of lipoproteins in sponges, it is known that lipoproteins have appeared early in evolution (120) and have been detected in ovaries of marine invertebrates, playing a role in lipid transport (16). So, we

Page $10 / 36$ 
expect that lipid transport occurs in a similar way in sponges, including the TG transport. In our transcriptomic data, GO enriched categories ("very-low-density lipoprotein particle assembly" and "lipoprotein particle binding") and overexpressed genes related to lipoprotein formation (Iow-density lipoprotein receptor-related protein, Irp; low density lipoprotein receptor adapter protein 1, Idlrap 1; low-density lipoprotein receptor, Idlr; apolipoprotein L3, apol3) in females, compared to NR (see paragraph 3 results) (Fig. 8A, C; Additional file 8: Table S5; Additional file 9: Table S6; Additional file 10: Table S7), strengthen our hypothesis. Furthermore, vitellogenin receptors, which are lipoproteins related to yolk formation in egglaying species (121), have been identified in other demosponges $(122,123)$. In $P$. ventilabrum, genes expressing both vitellogenin and its receptor were three times more expressed in the Vi_I female than NR, although they did not qualify as differentially expressed in our analysis.

Lipids with high number of unsaturations (PUFAs with $\geq 3$ unsaturations), including PUFA TGs, had their signal decreased towards females with more mature oocytes (Fig. 6; Additional file 3: Table S2). The largest variation of PUFAs was observed in samples between the different locations/months (Fig. 4), indicating that these lipids are mostly related to nutrients in the environment. During oogenesis, these lipids might be used/oxidized to provide fast energy to the adult because they are more unstable than the SFAs or MFAs. Specimens that do not reproduce, potentially, store them for other future physiological functions and/or consume them at a slower pace than the reproductive specimens, and that is why we observed a higher signal in specimens without oocytes in their mesohyl (Fig. 6D). Even though the mechanism of PUFA oxidation in sponges is not known, based on the mechanism of peroxisomal PUFA oxidation in mammals (124), we could not find any upregulated gene related to PUFA oxidation. In addition the decrease of FA(22:6), (normally produced after PUFA oxidation in mammals (125)) and of their oxylipins (HDoHEs), do not suggest either an increase of the PUFAs oxidation, at least in a similar way to what happens in mammals. It might be the case that sponges follow a different mechanism of PUFA oxidation, and further studies are needed to investigate this.

While the PUFA oxidation route in sponges might be novel, it is also possible that PUFAs in sponges are oxidized via the regular FA oxidation route in mitochondria. Indeed, we found a higher activity of genes related to FA beta-oxidation in females compared to NR (Fig. 8B-C, Additional file 12: Fig. S2), including activation and transportation of FA to the mitochondria by acs, carnitine:palmitoy/transferase, $c p t$, and mitochondrial carnitine/acylcarnitine carrier protein, Slc25a20) (126) and their beta-oxidation to produce acyl-CoA, the main component entering the citric cycle. This overexpression indicates that there was an increase in FA beta-oxidation due to high energetic requirements during oogenesis. Indeed, most of the carbon accumulated in sponges (90\%) is spent in generating energy for physiological processes such as growth, pumping and reproduction (Koopmans, 2009), and lipids are a large source used for oxidation in sponges as they consist of more than $50 \%$ of the dry weight of the particulate organic matter that sponges feed on (127). Therefore, we cannot discard alternative routes for lipid oxidation to provide energy in sponges. The extra enzymes required for the oxidation of unsaturated FA, either for odd or even number of carbons $(\operatorname{Delta}(3,5)$-Delta $(2,4)$ dienoyl-CoA isomerase, ech1; and 2,4-dienoyl-CoA reductase, decr1) were detected in our analysis, however, without overexpression in females. This suggests either that these FA might be absorbed for production of other lipids, or that maybe, again, there is a different mechanism for oxidising these lipids in sponges.

Lastly, the oxylipins seem to have a strong negative correlation with the female reproduction, and only the prostaglandins $\mathrm{PGF}_{2}$ and $\mathrm{PGF}_{2 \mathrm{a}}$ showed an increase in their signal in the tissues with oocytes developing in $P$. ventilabrum. The hormonal regulation of reproduction has not been studied in sponges so far, but in mammals prostaglandins regulate several processes of female reproduction, including oocyte maturation, ovulation and fertilization (e.g. Sugimoto et al., 2015), and this could be potentially the case here.

One of the major limitations of our study is that we explored the lipidome and the gene regulation of the whole sponge and not isolated cells and so we observed the parallel physiological processes occurring in different cells at the same time. For instance, while in oocytes the generation of TGs might occur, in other cells oxidation of PUFA TGs and other lipids for energy production can probably happen. Further studies with a focus on targeted cells would be necessary to understand 
in depth these processes. In addition, the characterisation of the specific structure of lipids and the tracing with isotope labelling would enhance our comprehension on the role of nutrient uptake from the surrounding to the pathways of FA incorporation for synthesis of other lipids, to the yolk formation during oogenesis in sponges, and their route of oxidation.

\section{Conclusions}

This is the first study in which the reproductive strategy of the sponge $P$. ventilabrum, a keystone species of the vulnerable deep-sea sponge grounds of North Atlantic is investigated. It is also the first application of semi-targeted lipidomics to a sponge, which allowed us to detect a total of hundreds different lipids by retention time and $\mathrm{m} / \mathrm{z}$, more sponge lipids than any other previous work. Furthermore, we detected lipids that are absent or in low amounts in mammals, such as phytosphingolipids and glycerophospholipids of methylethanolamine or dimethylethanolamine. This illustrates the outstanding diversity of the sponge "chemical dark matter" often difficult to comprehend, and that new metabolomic methods are just starting to reveal. The findings of this study have important ecological and evolutionary implications. Information for the reproductive activity and strategy of $P$. ventilabrum enhances our understanding on ecosystem services of sponge grounds and can contribute to developing conservation strategies in these areas. Additionally, the understanding of the lipid content dynamics during reproduction could also give an idea on the fitness of the propagules and how inbalances in lipid resources in the environment could affect the fitness of the species. Finally, this study provides essential information for understanding the origin of the lipid yolk content in Metazoa.

\section{Methods}

\section{Sample collection}

Specimens of $P$. ventilabrum were collected in Langenuen and Korsfjord (Western Norway, depth: 95-332 m) in September 2016 and in Kosterfjord (Sweden, depth: 89-91 m) at the end of March 2019 (Table 1). Collections were done either with a Remote Operated Vehicle (ROV) (Kosterfjord) or a triangular dredge (Langenuen/Korsfjord). No special permission was needed for the sponge sampling in Norway while a permit was given by Tjärnö Marine station, Sweden, for sponge collection within the national park at the Kosterfjord. Specimens were identified based on external morphology and spicules by P. Cárdenas and H.T. Rapp (slides for spicule preparations are available upon request to PC and AR). On board, three $\sim 5 \mathrm{~mm}^{3}$ pieces were cut with sterile and RNAse-free instruments from different parts of each specimen and fixed in $2.5 \%$ glutaraldehyde solution for histological analysis. Another three $\sim 5 \mathrm{~mm}^{3}$ pieces, from the same specimens, were fixed in RNAlater ${ }^{\text {TM }}$ Stabilization Solution (Thermo Fisher Scientific). For lipidomics, a large piece of each specimen was flash frozen in liquid nitrogen, transported in dry ice to Uppsala University and kept at $-80^{\circ} \mathrm{C}$ until freeze-drying for the lipidomic analysis.

\section{Histological Analysis}

Sample preparation for histological analyses was done according to the protocol by Koutsouveli et al. (2020a, b). In brief, the fresh collected samples, once in the lab, were first rinsed in a solution of $0.6 \mathrm{M} \mathrm{NaCl}$ and $0.4 \mathrm{M}$ PBS and then post fixed in $2 \%$ osmium tetroxide in $0.4 \mathrm{M}$ PBS for two hours and incubated overnight in $4 \%$ hydrofluoric acid (HF) to remove any silica structures from their skeleton. Afterwards, samples were rinsed with distilled water and dehydrated with ethanol in an ascending series (50-70-96-100\%). For light microscopy, samples were then embedded in paraffin blocks and those were cut with a HM325 microtome (ThermoFisher Scientific) into sections of $5 \mu \mathrm{m}$, which were stained with a standard Harris' Hematoxylin and Eosin (HandE) protocol. Histological sections were observed with an Olympus microscope (BX43) with an attached UC50 camera. For transmission electron microscopy (TEM), samples were embedded in LRW resin blocks (agar Scientific) (according to the guidelines of the manufacturer) and those cut at $60 \mathrm{~nm}$ in a Ultracut ReichertJung ultramicrotome. Then, the sections were stained with $2 \%$ uranyl acetate/lead citrate (129), and observed with a Hitachi TEM Microscope (H-7650) at 80kV.

Page $12 / 36$ 
We then measured the size and number of gametes within reproductive females with the Olympus Microimaging software CellSens standard, integrated to the Olympus microscope, on the histological sections. Several tissue areas $\left(0.58 \mathrm{~mm}^{2}\right.$ each area) of each section were surveyed for the measurements, avoiding to outnumber the density of the gametes within the tissue. All the images for measurements were taken at 10x magnification. To extract the final measurements, we calculated the average and the standard deviation of the size of the gametes from all the different images. We also conducted quantification of the different types of yolk content within the oocytes with ImageJ (130) on the TEM images.

Information extracted from the histological observations of the reproductive specimens, regarding the developmental stage of their oocytes, was further used for the lipidomic and transcriptomic analyses. Specifically, for the lipidomic analysis the area of sponge tissue occupied by oocytes was taken into account in order to observe the variation of lipid signal. As the number of oocytes did not change in the different developmental stages of oogenesis, the increase of sponge tissue occupied by oocytes was proportional to the maturation stage of the oocytes. For transcriptomic analysis, individuals with reproductive elements were classified to Vi_I or Vi_Il stages, based on the developmental stage of their oocytes observed in the histological sections, while nonreproductive specimens (NR) did not have any gametes. Vi_II stages contain the most mature oocytes, which are larger in size and have greater yolk content than the Vi_l individuals.

\section{Lipidome Analysis}

\subsection{Semi-targeted Lipidomics}

The samples from the different locations (Langenuen/Korsfjord and Kosterfjord) were processed in different batches. Frozen subsamples were freeze-dried and grinded in a falcon tube; $52 \pm 2 \mathrm{mg}$ and $22 \pm 1.2 \mathrm{mg}$ of powder was extracted for the samples of Langenuen /Korsfjord and Kosterfjord respectively (Additional file 13: Table S9A). The extraction was done with chloroform, based on Bligh and Dyer protocol (131). Briefly, we incubated the samples in 1:2 chloroform/methanol ( $/ \mathrm{v}$ ) overnight. The organic phase (lower phase) was collected after centrifugation, mixed with $375 \mu \mathrm{L}$ of $\mathrm{CHCl}_{3}$ and incubated for another 24 hours. The organic phases from the two extractions were pooled $(1 \mathrm{~mL})$ together and dried under vacuum. The samples were resuspended in $200 \mu \mathrm{L}$ of ACN/IPA 50:50. We also prepared the quality control (QC) in which we mixed $10 \mu \mathrm{L}$ from all the extracted specimens. The separation was slightly modified from (132). Briefly, lipids were separated by Ultra High-Performance Liquid Chromatography (UHPLC) with a BEH C18 column (1.7 $\mu \mathrm{m}, 2.1 \times 150 \mathrm{~mm})$ on an Acquity chromatographer hyphenated to a Synapt G2S QToF (Waters, Manchester UK). The mobile phases were A) water/acetonitrile/isopropanol 40:30:30 (v/v/v) with $5 \mathrm{mM}$ of ammonium formate, and B) acetonitrile/isopropanol 40:60 $(\mathrm{v} / \mathrm{v})$ with $5 \mathrm{mM}$ of ammonium formate. The gradient (flow $0.275 \mathrm{~mL} \mathrm{~min}^{-1}$ ) changed linearly as in Additional file 13: Table S9B. The ionization was carried out by electrospray in positive and negative modes. The injections of QC were four at the beginning and at the end of the injections as well as between every five injections of the samples. During the extraction protocol and injection, the order of the samples was randomized.

\subsection{Oxylipin quantification}

For the extraction of oxylipins we followed the protocol by (133). In detail, $30 \pm 6 \mathrm{mg}$ of tissue for each specimen (Additional file 13: Table S9A) were mixed with $2 \mathrm{~mL}$ of methanol and sonicated for $30 \mathrm{~min}$ on ice to enhance the extraction. After centrifugation $(15 \mathrm{~min}$ at $3,000 \mathrm{~g})$, the supernatant $(1.5 \mathrm{~mL})$ was transferred into Pyrex extraction tubes. We evaporated the solvent with nitrogen (TurboVap LV) until reaching an approximate volume of $300 \mu \mathrm{L}$ and then we added $2.7 \mathrm{~mL}$ of Solid Phase Extraction (SPE) buffer (pH 5.6). SPE was performed in order to eliminate any interferences that could add background signals to our analysis using an Extrahera automated system. After loading the column with the extract, we washed with $2.5 \mathrm{~mL}$ of $90: 10 \mathrm{H}_{2} \mathrm{O} / \mathrm{MeOH}(\mathrm{v} / \mathrm{v})$ and the extract of interest was eluted with $100 \% \mathrm{MeOH}$. The eluent was dried under nitrogen (TurboVapLVTM evaporator) and resuspended in $100 \mu \mathrm{L}$ of 85:15 MeOH/ $\mathrm{H}_{2} \mathrm{O}(\mathrm{v} / \mathrm{v})$. Finally, the samples were filtered with $0.1 \mu \mathrm{m}$ nylon filters (Amicon Ultrafree-MC) by centrifuging at $5,000 \mathrm{~g}$ for $3.5 \mathrm{~min}$ at $4^{\circ} \mathrm{C}$. We collected approximately $80 \mu \mathrm{L}$ of the final extract and $8 \mu \mathrm{L}$ were injected on a BEH C18 column $(1.7 \mu \mathrm{m}, 2.1 \times 150 \mathrm{~mm})$. For 
chromatographic separation and lipid quantification, we used an Acquity UPLC coupled to Triple Quadrupole Mass

Spectrometer, TQS-S ${ }^{\text {TM }}$ instrument (Waters, Milford, USA), operated in negative mode. Mobile phases consisted of A, water with $0.1 \%$ of acetic acid and $B$, acetonitrile/isopropanol $90: 10$. Column temperature was $60^{\circ} \mathrm{C}$ and flow rate was $0.5 \mathrm{~mL}$ $\min ^{-1}$ with a gradient initiated at $90 \%$ of $A$ that changed linearly to $65 \%$ in $\min 3.5$, to $60 \%$ in $\min 5.5$, to $58 \%$ in $\min 7$, to $50 \%$ in $\min 9$ and to $35 \%$ in min 15 . Further details about the mass spectrometry parameters can be found in (134).

\subsection{Data pre-treatment}

For lipidomics data-pretreatment we followed (132). Briefly, Water's raw mass spectrometry files were transformed with Data Bridge into CDF files and processed with XCMS package in R $(135,136)$. To identify the lipids, a database of lipids from Lipid Maps was used (137). For this database, the $\mathrm{m} / \mathrm{z}$ of the different adducts was generated in $\mathrm{R}$ by package Rdisop in R (138). For every lipid, the family the adduct, the total number of carbons and the total number of unsaturations were identified from the combination of $\mathrm{m} / \mathrm{z}$ and retention time of the first and the second isotopologues (Additional file 1 : Table S1). When possible, because of the intensity, the fatty acids were identified by the fragmentation patterns (Additional file 13: Table S10). The lipid signal was quantified as the area under the chromatographic curve of the peaks. For every specimen, the lipid signal was normalized by the weight of sample extracted in $\mathrm{mg}$.

Regarding oxylipins, for the quantification, a calibration curve with 11 external points, spiked with internal standards was used $(133,134)$. Concentration calculations were performed in TargetLynx (Waters, Milford, USA). Finally, the amount of oxylipins were normalized as ng of oxylipin per $\mathrm{g}$ of dry sponge extracted.

\subsection{Statistical Analysis}

First, to study the factor location/month, we used a principal component analysis (PCA) and we applied multiple t-tests for the main lipid categories (FFA, PC, LPC, TG, PE, LPE, PG, LPG and sphingolipids) and subcategories according to the number of saturations (SFA; MFA; PUFA) in order to observe variations between the two different sampling locations/months. In the case of oxylipins, the data were available only for specimens from one location (Langenuen/Korsfjord) so, they were not included in this analysis. Significant variations had an adjusted $p$-value (based on Benjamini and Hochberg, BH; FDR) $\leq 0.05$.

To isolate the effect of the reproduction status from location, we performed multivariate regression on the logarithm of the signal of the lipids of all the identified lipid categories by using the percentage of the area of sponge tissue occupied by oocytes as predictor. Consequently, the coefficient for the percentage of the area of the sponge tissue occupied by oocytes represented the upregulation (positive coefficient) or downregulation (negative coefficient) of the lipid with the development of oocytes (Additional file 3: Table S2). From nonreproductive to female individuals with most mature oocytes in their tissue, the area of the tissue occupied by oocytes increased. For the analysis, each lipid category was analysed (Additional file 1: Table S1; Additional file 3: Table S2).

All the statistical and graphical analyses were conducted in R (R Core Team 2017).

\section{Transcriptomic Analysis}

\subsection{RNA extraction and library preparation}

Given logistic and sampling limitations, only four samples of $P$. ventilabrum from Langenuen/ Korsfjord were used for the transcriptomic analysis (Table 1, with asterisks): two females and two nonreproductive specimens. The protocols used for RNA isolation, mRNA purification and cDNA library preparation were described in Koutsouveli et al. (123). Briefly, total RNA extraction was conducted with a standard TRIzol ${ }^{\mathrm{TM}}$ Reagent (ThermoFisher Scientific) protocol, according to the guidelines of the manufacturer. Further mRNA purification was performed with the Dynabeads mRNA DIRECT kit (ThermoFisher Scientific), applying the final stage of the protocol, 'Elimination of rRNA contamination'. The quantity and quality of mRNA 
were assessed by NanoDrop 2000 (ThermoFisher Scientific). Then, cDNA libraries were prepared with Scriptseq v2 kit (Illumina) (according to the manufacturer's instructions), using an initial mRNA quantity of 50 ng. The amount of cDNA was then assessed with Qubit ${ }^{\text {TM }}$ dsDNA HS Assay kit (ThermoFisher Scientific) and the quality with an Agilent Tapestation 2200 system (Agilent Technologies). The sequencing was done in an Illumina NextSeq 500 platform at the Natural History Museum of London sequencing facility (Molecular Core Labs).

\title{
4.2 Assembly, Differential Gene Expression Analysis, Annotation
}

Filtering of reads based on quality was performed with Trimmomatic (139), and the de novo assembly was done with Trinity v2.8.4 (140). Completeness of the assembly was calculated with Benchmarking Universal Single-Copy Orthologs (Busco V2/3) against metazoan cassettes (141). For gene expression analyses, mapping of the reads to the reference assembly was performed with Bowtie2 (142), transcript quantification was done with RSEM (143), and differential gene expression (DGE) analysis was conducted with edgeR $(144,145)$. We did pairwise comparisons of each female specimen $v s$ the two nonreproductive specimens, as the two female specimens were in different developmental stages (Vi_Il containing more mature oocytes than $\mathrm{Vi} \_$I). Therefore, due to lack of replication for the reproductive condition, we used dispersion 0.1 for the conduction of DGE analysis with edgeR.

\subsection{Gene Ontology and KEGG enrichment analysis}

For the transcriptome annotation, we did a blastx search (146) of the transcriptome using the swissprot database (147) containing only metazoan proteins (accessed in 2020), using Diamond (148) with a cut-off evalue of $1 \mathrm{e}-5$. The sequences with blast hits were further annotated by Blast2GOPRO (149) to retrieve the functional information from the Gene Ontology (GO) terms.

We then performed a GO enrichment analysis using a Fisher's Exact Test in Blast2GOPRO (149) with a $p$-value threshold of $\leq 0.05$. This analysis was conducted using as "test dataset" the upregulated genes of each female developmental stage separately (Vi_I, Vi_II) vs nonreproductive individuals and as "reference dataset" the total annotation file of the reference transcriptome. The percentage of sequences contained in each GO term was extracted and used for the depiction of a bubble graph in R (R Core Team, 2018). In some cases, more than one sequence was linked to the same process, so we added the relevant sequences to have a final summary percentage.

In addition, we performed a KEGG analysis (150) in Blast2GOPRO (149) in order to see which biochemical pathways were activated and enriched in Vi_I developmental stage and in Vi_Il stage separately, when compared to nonreproductive specimens.

\section{List Of Abbreviations}

\author{
AA arachidonic acid
}

ALA a-linolenic acid

BUSCO benchmarking universal single-copy orthologs

DGE differential gene expression

DHA docosahexaenoic acid

DiHETE dihydroxyeicosatetraenoic acid

DiHETrE dihydroxyeicosatrienoic acid 
EPA eicosapentaenoic acid

EpDPE epoxydocosapentaenoic acid

EpETE epoxyeicosatetraenoic acid

EpETrE epoxyeicosatrienoic acid

FDR false discovery rate

FFA free fatty acid

GO Gene Ontology

HDoHE hydroxydocosahexaenoic acids

HEPE hydroxyeicosapentaenoic acid

HETE hydroxyeicosatetraenoic acid

HETrE hydroxyeicosatrienoic acids

HHTrE hydroxyheptadecatrienoic acid

HODE hydroxy-octadecadienoic acid

HOTrE hydroxyoctadecatrienoic acid

KEGG kyoto encyclopedia of genes and genomes

KETE oxoeicosatetraenoic acid

KODE oxo-octadecadienoic acid

LA linoleic acid

LMA low microbial abundant

LPC lysophosphatidylcholines

LPE lysophosphatidylethanolamine

LPG phosphatidylglycerol

$\mathrm{LXA}_{4}$ lipoxin $\mathrm{A}_{4}$

$\mathrm{LXA}_{5}$ lipoxin $\mathrm{A}_{5}$

MFA mono-unsaturated fatty acid

NR nonreproductive

PBS phosphate-buffered saline

PC phosphatidylcholine 
PCA principal component analysis

PE phosphatidylethanolamine

PG phosphatidylglycerol

$\mathrm{PGD}_{2}$ prostaglandin $\mathrm{D}_{2}$

$\mathrm{PGE}_{2}$ prostaglandin $\mathrm{E}_{2}$

$\mathrm{PGE}_{3}$ prostaglandin $\mathrm{E}_{3}$

PGF $_{2 a}$ prostaglandin $F_{2 a}$

PGF $_{3 a}$ prostaglandin $\mathrm{F}_{3 a}$

PUFA poly-unsaturated fatty acid

PV previtellogenic

Q-ToF Quadrupole Time-of-Flight

ROV remote operated vehicle

RSEM RNA-Seq by expectation-maximization

SFA saturated fatty acid

SPE solid phase extraction

TEM transmission electron microscopy

TG triacylglyceride

TQ-MS triple quadrupole mass spectrometer

UHPLC-MS ultra-high performance liquid chromatography mass spectroscopy

Vi_I Vitellogenic stage I

Vi_II Vitellogenic stage II

\section{Declarations}

\section{Ethics approval and consent to participate}

Not applicable

Consent for publication

Not applicable

Availability of data and materials

Page 17/36 
The raw reads generated for the transcriptomic analysis of this study were deposited at Sequence Read Archive (SRA) with BioProject ID: PRJNA64180 and submission ID: SUB7667177.

\section{Competing interests}

The authors declare that they have no competing interests

\section{Funding}

This work was supported by the H2020 EU Framework Programme for Research and Innovation Project SponGES (Deepsea Sponge Grounds Ecosystems of the North Atlantic: an integrated approach towards their preservation and sustainable exploitation) (Grant Agreement no. 679849). This document reflects only the authors' view and the Executive Agency for Small and Medium-sized Enterprises (EASME) is not responsible for any use that may be made of the information it contains. Funding was also provided by a grant of the Spanish Ministry of Science and Innovation (PID2019-105769GBI00) to AR. The funding bodies did not have any role in the design of the study, the analysis or the data interpretation.

\section{Authors' contributions}

VK: sample collection, histological preparation, lipid extraction, RNA and library preparation, data analysis, writing of the manuscript; DB: lipid extraction, data analysis, writing of the manuscript, AC: oxylipin extraction, $\mathrm{MH}$ : data analysis, writing of the manuscript, AR: conceptualization of the project, sample collection, supervision of the project, writing of the manuscript, PC: sample collection, supervision of the project, writing of the manuscript. All the authors have read and approved the manuscript.

\section{Acknowledgements}

We would like to thank María Conejero for her important help in electron microscopy sections, Karin Steffen for her essential help on sample collection, and the analysis of the data, Dr. Christina Diez for her help on the analysis of the data, Dr. Francisca Carvalho (University of Bergen), Dr. Joana Xavier (University of Bergen) and Prof. Hans Tore Rapp (University of Bergen) for their help and support during sample collection. We also thank the crews of the research vessels $R / V$ Hans Brattstrøm (University of Bergen) and R/V Nereus (Gothenburg University).

\section{References}

1. Bergé J-P, Barnathan G. Fatty Acids from Lipids of Marine Organisms: Molecular Biodiversity, Roles as Biomarkers, Biologically Active Compounds, and Economical Aspects. Adv Biochem Eng Biotechnol. 2005;96:49-125.

2. Parzanini C, Parrish C, Hamel J, Mercier A. Functional diversity and nutritional content in a deep-sea faunal assemblage through total lipid, lipid class, and fatty acid analyses. PLoS One. 2018;13(11):e0207395.

3. Parrish CC. Lipids in Marine Ecosystems. ISRN Oceanogr. 2013;2013:1-16.

4. Parrish CC, Abrajano T, Budge S, Helleur R, Hudson E, Pulchan K, et al. Lipid and Phenolic Biomarkers in Marine Ecosystems: Analysis and Applications. In: Wangersky P.J., editor. Marine Chemistry The Handbook of Environmental Chemistry (Vol 5 Series: Water Pollution). Springer Berlin Heidelberg; 2000.

5. Laender F De, Oevelen D Van, Frantzen S, Middelburg JJ, Soetaert K. Seasonal PCB bioaccumulation in an arctic marine ecosystem: a model analysis incorporating lipid dynamics, food-web productivity and migration. Environ Sci Technol. 2010 Jan;44(1):356-61.

6. Bianchi T, Canuel E. Chemical Biomarkers in Aquatic Ecosystems [Internet]. Princeton University Press; 2011. 
7. Signa G, Di Leonardo R, Vaccaro A, Tramati CD, Mazzola A, Vizzini S. Lipid and fatty acid biomarkers as proxies for environmental contamination in caged mussels Mytilus galloprovincialis. Ecol Indic. 2015;57:384-94.

8. Brett M, Mueller-Navarra D, Persson J. Crustacean Zooplankton Fatty Acid Composition. In: Kainz M, Brett M, Arts M, editors. Lipids in Aquatic Ecosystems. New York: Springer; 2009. p. 115-46.

9. Martin-Creuzburg D, Elert E. Ecological Significance of Sterols in Aquatic Food Webs. In: Kainz M, Brett M, Arts M, editors. Lipids in Aquatic Ecosystems. New York: Springer; 2009. p. 43-64.

10. Parrish C. Essential fatty acids in aquatic food webs. In: Kainz M, Brett M, Arts M, editors. Lipids in aquatic ecosystems. New York: Springer; 2009. p. 309-26.

11. Maier SR, Bannister RJ, van Oevelen D, Kutti T. Seasonal controls on the diet, metabolic activity, tissue reserves and growth of the cold-water coral Lophelia pertusa. Coral Reefs 2020;39(1):173-87.

12. Phleger CF. Buoyancy in Marine Fishes: Direct and Indirect Role of Lipids. Am Zool. 1998;38(2):321-30.

13. Pond DW, Tarling GA. Phase transitions of wax esters adjust buoyancy in diapausing Calanoides acutus. Limnol Oceanogr. 2011;56(4):1310-8.

14. Giese AC. Lipids in the economy of marine invertebrates. Physiol Rev. 1966;46(2):244-98.

15. Joseph JD. Distribution and Composition of Lipids in Marine Invertebrates. In: Ackman RG, editor. Marine Biogenic Lipids, Fats and Oils. CRC Press, Boca Raton; 1989. p. 49-143.

16. Lee RF. Lipoproteins from the Hemolymph and Ovaries of Marine Invertebrates. In: Houlihan DF, Livingstone DR, Lee RF, editors. Advances in Comparative and Environmental Physiology. Berlin, Heidelberg: Springer Berlin Heidelberg; 1991. p. 187-207.

17. Kattner G, Hagen W. Lipid metabolism of the Antarctic euphausiid Euphausia crystallorophias and its ecological implications. Mar Ecol Prog Ser. 1998;170:203-13.

18. Heras H, Pollero RJ, Gonzalez-Baró MR, Pollero RJ. Lipid and fatty acid composition and energy partitioning during embryo development in the shrimp Macrobrachium borellii. Lipids 2000;35(6):645-51.

19. Viladrich N, Bramanti L, Tsounis G, Chocarro B, Martínez-Quitana A, Ambroso S, et al. Variation in lipid and free fatty acid content during spawning in two temperate octocorals with different reproductive strategies: surface versus internal brooder. Coral Reefs. 2016;35(3):1033-45.

20. Hansen M, Flatt T, Aguilaniu H. Reproduction, fat metabolism, and lifespan- What is the connection? Cell Metab. 2013;17(1):10-9.

21. Strathmann RR. Egg Size, Larval Development, and Juvenile Size in Benthic Marine Invertebrates. Am Nat. 1977;111(978):373-6.

22. Pechenik J. Delayed metamorphosis by larvae of benthic marine-invertebrates-does it occur? Is There a Price to Pay? Ophelia. 1990;32:63-94.

23. Harms J. Larval development and delayed metamorphosis in the hermit crab Clibanarius erythropus (Latreille) (Crustacea, Diogenidae). J Exp Mar Bio Ecol. 1992;156(2):151-60. 
24. Harii S, Kayanne H, Takigawa HT, Hayashibara TH, Yamamoto M. Larval survivorship, competency periods and settlement of two brooding corals, Heliopora coerulea and Pocillopora damicornis. Mar Biol. 2002;141:39-46.

25. Doughty P, Shine R. Detecting life history trade-offs: measuring energy stores in "capital" breeders reveals costs of reproduction. Oecologia 1997;110(4):508-13.

26. Coma R, Ribes M, Gili J-M, Zabala M. An energetic approach to the study of life-history traits of two modular colonial benthic invertebrates. Mar Ecol Prog Ser. 1998;162:89-103.

27. Rossi S, Gili J-M, Coma R, Linares C, Gori A, Vert N. Temporal variation in protein, carbohydrate, and lipid concentrations in Paramuricea clavata (Anthozoa, Octocorallia): evidence for summer-autumn feeding constraints. Mar Biol. 2006;149(3):643-51.

28. Lee RF, Hagen W, Kattner G. Lipid storage in marine zooplankton. Mar Ecol Prog Ser. 2006;307:273-306.

29. Kattner G, Graeve M, Hagen W. Marine Biology. Mar Biol. 1994;644:18119.

30. Mourente G, Medina A, González S, Rodríguez A. Variations in lipid content and nutritional status during larval development of the marine shrimp Penaeus kerathurus. Aquaculture. 1995;130(2-3):187-99.

31. Marshall CT, Yaragina NA, Lambert Y, Kjesbu OS. Total lipid energy as a proxy for total egg production by fish stocks. Nature. 1999;402(6759):288-90.

32. Marshall CT, Yaragina NA, Ådlandsvik B, Dolgov A V. Reconstructing the stock-recruit relationship for Northeast Arctic cod using a bioenergetic index of reproductive potential. Can J Fish Aquat Sci. 2000;57(12):2433-42.

33. Dalsgaard J, St. John M, Kattner G, Müller-Navarra D, Hagen WBT-A in MB. Fatty acid trophic markers in the pelagic marine environment. In Academic Press; 2003. p. 225-340.

34. Bergquist PR, Lawson MP, Lavis A, Cambie RC. Fatty acid composition and the classification of the Porifera. Biochem Syst Ecol. 1984;12(1):63-84.

35. Djerassi C, Lam WK. Sponge Phospholipids. Acc Chem Res. 1991;24(3):69-75.

36. Thiel V, Blumenberg M, Hefter J, Pape T, Pomponi S, Reed J, et al. A chemical view of the most ancient metazoa Biomarker chemotaxonomy of hexactinellid sponges. Naturwissenschaften. 2002;89(2):60-6.

37. Velosaotsy N, Genin E, Nongobienma R, Al-Lihaibi S, Kornprobst J-M, Vacelet J, et al. Phospholipid distribution and phospholipid fatty acids in four saudi red sea sponges. Boll Mus Ist Biol Univ Genova. 2004;68:639-45.

38. Rod'kina SA. Fatty acids and other lipids of marine sponges. Russ J Mar Biol. 2005;31(Suppl. 1):S49-60.

39. Blumenberg M, Michaelis W. High occurrences of brominated lipid fatty acids in boreal sponges of the order Halichondrida. Mar Biol. 2007;150(6):1153-60.

40. Genin E, Wielgosz-Collin G, Njinkoué JM, Velosaotsy NE, Kornprobst JM, Gouygou JP, et al. New trends in phospholipid class composition of marine sponges. Comp Biochem Physiol - B Biochem Mol Biol. 2008;150(4):427-31.

41. Müller W, Rottmann M, Diehl-Seifert B, Kurelec B, Uhlenbruck G, Schröder HC. Role of the aggregation factor in the regulation of phosphoinositide metabolism in sponges. Possible consequences on calcium efflux and on mitogenesis. $J$ Biol Chem. 1987;262(20):9850-8. 
42. Weissmann G, Riesen W, Davidson S, Waite M. Stimulus-response coupling in marine sponge cell aggregation: lipid metabolism and the function of exogenously added arachidonic and docosahexaenoic acids. Biochim Biophys Acta. 1988;960(3):351-64.

43. Zivanovic A, Pastro NJ, Fromont J, Thomson M, Skropeta D. Kinase inhibitory, haemolytic and cytotoxic activity of three deep-water sponges from North Western Australia and their fatty acid composition. Nat Prod Commun. 2011;6(12):1921-4.

44. Shaaban M, Abd-Alla HI, Hassan AZ, Aly HF, Ghani MA. Chemical characterization, antioxidant and inhibitory effects of some marine sponges against carbohydrate metabolizing enzymes. Org Med Chem Lett. 2012;2(1):30.

45. Botić T, Cör D, Anesi A, Guella G, Sepčić K, Janussen D, et al. Fatty acid composition and antioxidant activity of Antarctic marine sponges of the genus Latrunculia. Polar Biol. 2015;38(10):1605-12.

46. Bennett H, Bell JJ, Davy SK, Webster NS, Francis DS. Elucidating the sponge stress response; lipids and fatty acids can facilitate survival under future climate scenarios. Glob Chang Biol. 2018;24(7):3130-44.

47. Carballeira NM. New advances in fatty acids as antimalarial, antimycobacterial and antifungal agents. Prog Lipid Res. 2008;47(1):50-61.

48. Kikuchi H, Tsukitani Y, Manda T, Fujii T, Nakanishi H, Kobayashi M, et al. Marine natural Products. X. Pharmacologically active glycolipids from the Okinawan marine sponge Phyllospongia foliascens (Pallas). Chem Pharm Bull. 1982;30:3544-7.

49. Natori T, Morita M, Akimoto K, Koezuka Y. Agelasphins, novel antitumor and immunostimulatory cerebrosides from the marine sponge Agelas mauritianus. Tetrahedron. 1994;50(9):2771-84.

50. Costantino V, Fattorusso E, Mangoni A, Di Rosa M, lanaro A. Glycolipids from Sponges. 6. Plakoside A and B, two unique prenylated glycosphingolipids with Immunosuppressive activity from the marine sponge Plakortis simplex. J Am Chem Soc. 1997;119(51):12465-70.

51. Costantino V, Fattorusso E, Imperatore C, Mangoni A. Glycolipids from sponges. 11. Isocrasserides, novel glycolipids with a five-membered cyclitol widely distributed in marine sponges. J Nat Prod. 2002;65(6):883-6.

52. Maldonado M, Riesgo A. Reproduction in Porifera: a synoptic overview. Treballs la Soc Catalana Biol. 2008;59:2949.

53. Sciscioli M, Lepore E, Scalera-Liaci L, Gherardi M. Indagine ultrastrutturale sugli ovociti di Erylus discophorus (Schmidt) (Porifera, Tetractinellida). Oebalia. 1989;15:939-941.

54. Sciscioli M, Liaci LS, Lepore E, Gherardi M, Simpson TL. Ultrastructural study of the mature egg of the marine sponge Stelletta grubii (porifera demospongiae). Mol Reprod Dev. 1991 Apr 1;28(4):346-50.

55. Riesgo A, Taboada S, Sánchez-Vila L, Solà J, Bertran A, Avila C. Some like it fat: comparative ultrastructure of the embryo in two demosponges of the genus Mycale (order Poecilosclerida) from Antarctica and the Caribbean. PLoS One 2015;10(3):e0118805.

56. Watanabe Y. The Development of Two Species of Tetilla (Demosponge). NSR O U. 1978;29(1):71-106.

57. Gaino E, Sarà M. An ultrastructural comparative study of the eggs of two species of Tethya (Porifera, Demospongiae). Invertebr Reprod Dev. 1994;26(2):99-106. 
58. Maldonado M, Riesgo A. Gametogenesis, embryogenesis, and larval features of the oviparous sponge Petrosia ficiformis (Haplosclerida, Demospongiae). Mar Biol. 2009;156(10):2181-97.

59. Lanna E, Klautau M. Oogenesis and spermatogenesis in Paraleucilla magna (Porifera, Calcarea). Zoomorphology. 2010;129(4):249-61.

60. Koutsouveli V, Taboada S, Moles J, Cristobo J, Ríos P, Bertran A, et al. Insights into the reproduction of some Antarctic dendroceratid, poecilosclerid, and haplosclerid demosponges. PLoS One. 2018;13(2):1-24.

61. Fell PE. The involvement of nurse cells in oogenesis and embryonic development in the marine sponge, Haliclona ecbasis. J Morphol. 1969;127(2):133-49.

62. Simpson T. The cell biology of sponges. Springer, New York. 1984;

63. Bellairs R. The structure of the yolk of the hen's egg as studied by electron microscopy: i. the yolk of the unincubated egg. J Biophys Biochem Cytol. 1961;11(1):207-25.

64. Maldonado M, Riesgo A. Reproduction in the phylum Porifera: a synoptic overview. Treballs la SCB. 2008;59:29-49.

65. Ereskovsky A. The comparative embryology of sponges. Springer; 2010. 1-323 p.

66. Watanabe Y. The Development of Two Species of Tetilla (Demosponge). Nat Sci Rep. 1978;29:71-106.

67. Sarà A, Cerrano C, Sarà M. Viviparous development in the Antarctic sponge Stylocordyla borealis Loven, 1868. Polar Biol. 2002;25(6):425-31.

68. Busch K, Wurz E, Rapp HT, Bayer K, Franke A, Hentschel U. Chloroflexi Dominate the Deep-Sea Golf Ball Sponges Craniella zetlandica and Craniella infrequens Throughout Different Life Stages. Front Mar Sci. 2020;7:674.

69. Koopmans M, van Rijswijk P, Boschker HTS, Marco H, Martens D, Wijffels RH. Seasonal Variation of Fatty Acids and Stable Carbon Isotopes in Sponges as Indicators for Nutrition: Biomarkers in Sponges Identified. Mar Biotechnol. 2015;17(1):43-54.

70. Lüskow F, Kløve-Mogensen K, Tophøj J, Pedersen LH, Riisgård HU, Eriksen NT. Seasonality in lipid content of the demosponges Halichondria panicea and H. bowerbanki at two study sites in temperate Danish waters. Front Mar Sci. 2019; (6):1-7.

71. Reiswig H. Population dynamics of three jamaican demospongiae. Bull Mar Sci. 1973;23:191-226.

72. Elvin DW. Seasonal Growth and Reproduction of an Intertidal Sponge, Haliclona permollis (Bowerbank). Univ Chicago Press. 1976;151(1):108-25.

73. Elvin DW. The relationship of seasonal changes in the biochemical components to the reproductive behavior of the intertidal sponge, Haliclona permollis. biol Bull. 1979;156:47-61.

74. Schmidt O. Die Spongien der Küste von Algier. Mit Nachträgen zu den Spongien des Adriatischen Meeres (Drittes Supplement). (Wilhelm Engelmann: Leipzig): i-iv, 1-44, pls I-V. 1868;

75. Ivanisevic J, Pérez T, Ereskovsky A V, Barnathan G, Thomas OP. Lysophospholipids in the Mediterranean Sponge Oscarella tuberculata: Seasonal Variability and Putative Biological Role. J Chem Ecol. 2011;37(5):537. 
76. Klitgaard AB. The fauna associated with outer shelf and upper slope sponges (Porifera, demospongiae) at the Faroe islands, North-eastern Atlantic. 1995;80(1):1-22.

77. Klitgaard AB, Tendal O. Distribution and species composition of mass occurrences of large-sized sponges in the northeast Atlantic. Prog Oceanogr. 2004;61:57-98.

78. Kutti T, Bannister RJ, Fosså JH. Community structure and ecological function of deep-water sponge grounds in the Traenadypet MPA - Northern Norwegian continental shelf. 2013;69:21-30.

79. Pile A, Young C. The natural diet of a hexactinellid sponge: Benthic-pelagic coupling in a deep-sea microbial food web. Deep Sea Res Part I Oceanogr Res Pap. 2006;53:1148-56.

80. Yahel G, Whitney F, Reiswig HM, Eerkes-Medrano DI, Leys SP. In situ feeding and metabolism of glass sponges (Hexactinellida, Porifera) studied in a deep temperate fjord with a remotely operated submersible. Limnol Oceanogr. 2007;52(1):428-40.

81. Hoffmann F, Radax R, Woebken D, Holtappels M, Lavik G, Rapp HT, et al. Complex nitrogen cycling in the sponge Geodia barretti. Environ Microbiol. 2009;11(9):2228-43.

82. Cathalot C, Van Oevelen D, Cox TJS, Kutti T, Lavaleye M, Duineveld G, et al. Cold-water coral reefs and adjacent sponge grounds: hotspots of benthic respiration and organic carbon cycling in the deep sea. Front Mar Sci. 2015;2:1-12.

83. Kahn A, Yahel G, Chu J, Tunnicliffe V, Leys S. Benthic grazing and carbon sequestration by deep-water glass sponge reefs. Limnol Oceanogr. 2015;60:78-88.

84. Rooks C, Fang JK-H, Mørkved PT, Zhao R, Rapp HT, Xavier JR, et al. Deep-sea sponge grounds as nutrient sinks: denitrification is common in boreo-Arctic sponges. Biogeosciences. 2020;17(5):1231-45.

85. Linnaeus C. Systema naturae per regna tria naturae: secundum classes, ordines, genera, species, cum characteribus, differentiis, synonymis, locis. Ed. 12. 1., Regnum Animale. 1 \& 2. Holmiae, Laurentii Salvii. 1767. pp. 5331327

86. Spetland F, Rapp HT, Hoffmann F, Tendal OS. Sexual reproduction of Geodia barretti Bowerbank, 1858 (Porifera, Astrophorida) in two Scandinavian fjords. In: Custódio M, Lôbo-Hajdu G, Hajdu E, Muricy G, editors. Porifera Research: Biodiversity, Innovation, Sustainability. Série Livros. Museu Nacional, Rio de Janeiro.; 2007. p. 613-20.

87. Koutsouveli V, Cárdenas P, Conejero M, Rapp HT, Riesgo A. Reproductive Biology of Geodia Species (Porifera, Tetractinellida) From Boreo-Arctic North-Atlantic Deep-Sea Sponge Grounds. Front Mar Sci. 2020;7:1-22.

88. Bowerbank JS. On the Anatomy and Physiology of the Spongiadae. Part I. On the Spicula. Philos Trans R Soc. 1858 ;

89. Wassmann P. Dynamics of primary production and sedimentation in shallow fjords and polls of western Norway. Oceanogr Mar Biol an Annu Rev. 1991;29:87-154.

90. Wassmann P, Svendsen H, Keck A, Reigstad M. Selected aspects of the physical oceanography and particle fluxes in fjords of northern Norway. J Mar Syst. 1996;8(1):53-71.

91. Bamstedt U. Life cycle, seasonal vertical distribution and feeding of Calanus finmarchicus in Skagerrak coastal water. Mar Biol. 2000;137(2):279-89. 
92. Linnaeus C. Systema Naturae per regna tria naturae, secundum classes, ordines, genera, species, cum characteribus, differentiis, synonymis, locis. Vol. 1, Editio decima, reformata. Laurentius Salvius: Holmiae. 1758.824 p.

93. Witte U. Seasonal reproduction in deep-sea sponges - triggered by vertical particle flux? Mar Biol. 1996;124(4):57181.

94. Southwood TR. Habitat, the Templet for Ecological Strategies. J Anim Ecol. 1977;46(2):336-65.

95. Clarke A. A reappraisal of the concept of metabolic cold adaptation in polar marine invertebrates. Biol J Linn Soc. 1980;14(1):77-92.

96. Eckelbarger KJ, Watling L. Role of Phylogenetic Constraints in Determining Reproductive Patterns in Deep-Sea Invertebrates. Invertebr Biol. 1995;114(3):256-69.

97. Busch K, Taboada S, Riesgo A, Koutsouveli V, Ríos P, Cristobo J, et al. Population connectivity of fan-shaped sponge holobionts in the deep Cantabrian Sea. Deep Sea Res Part I Oceanogr Res Pap. 2020;103427.

98. Riesgo A, Maldonado M. Ultrastructure of oogenesis of two oviparous demosponges: Axinella damicornis and Raspaciona aculeata (Porifera). Tissue Cell. 2009;41(1):51-65.

99. Whiteley NM, Taylor EW, el Haj AJ. A comparison of the metabolic cost of protein synthesis in stenothermal and eurythermal isopod crustaceans. Am J Physiol. 1996;271:R1295-303.

100. Pace DA, Manahan DT. Cost of protein synthesis and energy allocation during development of Antarctic sea urchin embryos and larvae. Biol Bull. 2007;212:115-29.

101. Sciscioli M, Lepore E, Gherardi M, Liaci LS. Transfer of symbiotic bacteria in the mature oocyte of Geodia cydonium (Porifera, Demosponsgiae): An ultrastructural study. Cah Biol Mar. 1994;35(4):471-8.

102. Bronson F. Mammalian reproductive biology. Chicago: University of Chicago Press; 1989.

103. McWilliams SR, Guglielmo C, Pierce B, Klaassen M. Flying, fasting, and feeding in birds during migration: a nutritional and physiological ecology perspective. J Avian Biol. 2004;35(5):377-93.

104. Derickson WK. Lipid Storage and Utilization in Reptiles. Am Zool. 1976;16(4):711-23.

105. Fraser AJ. Triacylglycerol Content as a Condition Index for Fish, Bivalve, and Crustacean Larvae. Can J Fish Aquat Sci. 1989;46(11):1868-73.

106. Bonnet X, Naulleau G, Mauget R. The influence of body condition on 17-beta estradiol levels in relation to vitellogenesis in female Vipera aspis (Reptilia, Viperidae). Gen Comp Endocrinol. 1994;93(3):424-37.

107. Duggan A, Paolucci M, Tercyak A, Gigliotti M, Small D, Callard I. Seasonal variation in plasma lipids, lipoproteins, apolipoprotein A-I and vitellogenin in the freshwater turtle, Chrysemys picta. Comp Biochem Physiol Part A, Mol \&amp; Integr Physiol. 2001;130(2):253-69.

108. Lance VA, Place AR, Grumbles JS, Rostal DC. Variation in plasma lipids during the reproductive cycle of male and female desert tortoises, Gopherus agassizii. J Exp Zool. 2002;293(7):703-11.

109. Kawazu I, Kino M, Yanagisawa M, Maeda K, Nakada K, Yamaguchi Y, et al. Signals of Vitellogenesis and Estrus in Female Hawksbill Turtles. Zoolog Sci. 2015;32(1):114-8. 
110. Teshima S ichi, Kanazawa A. Variation in Lipid Compositions during the Ovarian Maturation of the Prawn. Nippon Suisan Gakkaishi. 1983;49(6):957-62.

111. Clarke A, Brown JH, Holmes LJ. The biochemical composition of eggs from Macrobrachium rosenbergii in relation to embryonic development. Comp Biochem Physiol Part B Comp Biochem. 1990;96(3):505-11.

112. Allen W. Amino Acid and Fatty Acid Composition of Tissues of the Dungeness Crab (Cancer magister). J Fish Res. 1971;28:1191-5.

113. Rosa R, Nunes ML. Tissue biochemical composition in relation to the reproductive cycle of deep-sea decapod Aristeus antennatus in the Portuguese south coast. J Mar Biol Assoc.2003;83(5):963-70.

114. Balgoma D, Pettersson C, Hedeland M. Common Fatty Markers in Diseases with Dysregulated Lipogenesis. Trends Endocrinol Metab. 2019;30(5):283-5.

115. Kent C. Eukaryotic phospholipid biosynthesis. Annu Rev Biochem. 1995;64(1):315-43.

116. Coleman RA, Lee DP. Enzymes of triacylglycerol synthesis and their regulation. Prog Lipid Res. 2004;43(2):134-76.

117. Bell RM, Coleman RA. Enzymes of glycerolipid synthesis in eukaryotes. Annu Rev Biochem. 1980;49:459-87.

118. Mathews C, van Holde K, Appling D, Anthony-Cahill S. Biochemistry. 4th ed. Pearson; 2019. 1368 p.

119. Gavaud J. Histochemical identification of ovarian lipids during vitellogenesis in the lizard Lacerta vivipara. Can J Zool. 1991;69(5):1389-92.

120. Chapman MJ. Animal lipoproteins: Chemistry, structure, and comparative aspects. J Lipid Res. 1980;21(7):789853.

121. Dolphin PJ, Ansari AQ, Lazier CB, Munday KA, Akhtar M. Studies on the induction and biosynthesis of vitellogenin, an oestrogen-induced glycolipophosphoprotein. Biochem J. 1971;124(4):751-8.

122. Riesgo A, Farrar N, Windsor PJ, Giribet G, Leys SP. The analysis of eight transcriptomes from all poriferan classes reveals surprising genetic complexity in sponges. Mol Biol Evol. 2014;31(5):1102-20.

123. Koutsouveli V, Cárdenas P, Santodomingo N, Marina A, Morato E, Rapp HT, et al. The molecular machinery of gametogenesis in Geodia demosponges (Porifera): evolutionary origins of a conserved toolkit across animals. Mol Biol Evol. 2020;

124. Wanders RJA. Peroxisomes, lipid metabolism, and peroxisomal disorders. Mol Genet Metab. 2004;83(1):16-27.

125. Wanders RJA, Waterham HR, Ferdinandusse S. Metabolic Interplay between Peroxisomes and Other Subcellular Organelles Including Mitochondria and the Endoplasmic Reticulum. Vol. 3, Frontiers in Cell and Developmental Biology . 2016. p. 83.

126. Talley J, Mohiuddin S. Biochemstry, Fatty Acid Oxidation. StatPearls. 2020.

127. Reiswig HM. Particle Feeding in Natural Populations of Three Marine Demosponges. Biol Bull. 1971;141(3):56891.

128. Sugimoto Y, Inazumi T, Tsuchiya S. Roles of prostaglandin receptors in female reproduction. J Biochem. 2015 Feb $1 ; 157(2): 73-80$.

Page 25/36 
129. Reynolds ES. The use of lead citrate at high PH as an electron-opaque stain in electron microscopy. J Cell Biol. 1963;17(1):208-12.

130. Schneider CA, Rasband WS, Eliceiri KW. NIH Image to ImageJ: 25 years of image analysis. Nat Methods. 2012 Jul;9(7):671-5.

131. Bligh, E.G. and Dyer WJ. Canadian Journal of Biochemistry and Physiology. Can J Biochem Physiol. 1959;37(8):911-7.

132. Balgoma D, Zelleroth S, Grönbladh A, Hallberg M, Pettersson C, Hedeland M. Anabolic androgenic steroids exert a selective remodeling of the plasma lipidome that mirrors the decrease of the de novo lipogenesis in the liver.

Metabolomics. 2020;16(1):12.

133. Kolmert J, Piñeiro-Hermida S, Hamberg M, Gregory JA, López IP, Fauland A, et al. Prominent release of lipoxygenase generated mediators in a murine house dust mite-induced asthma model. Prostaglandins Other Lipid Mediat. 2018 Jul;137:20-9.

134. Balgoma D, Yang M, Sjödin M, Snowden S, Karimi R, Levänen B, et al. Linoleic acid-derived lipid mediators increase in a female-dominated subphenotype of COPD. Eur Respir J. 2016;47(6):1645 - 1656.

135. Smith CA, Want EJ, O'Maille G, Abagyan R, Siuzdak G. XCMS: processing mass spectrometry data for metabolite profiling using nonlinear peak alignment, matching, and identification. Anal Chem. 2006 Feb;78(3):779-87.

136. Tautenhahn R, Böttcher C, Neumann S. Highly sensitive feature detection for high resolution LC/MS. BMC Bioinformatics. 2008;9(1):504.

137. Fahy E, Sud M, Cotter D, Subramaniam S. LIPID MAPS online tools for lipid research. Nucleic Acids Res. 2007 Aug 1;35:W606-12.

138. Böcker S, Letzel MC, Lipták Z, Pervukhin A. SIRIUS: decomposing isotope patterns for metabolite identification. Bioinformatics. 2008 Nov 17;25(2):218-24.

139. Bolger AM, Lohse M, Usadel B. Trimmomatic: a flexible trimmer for Illumina sequence data. Bioinformatics [Internet]. 2014;30:2114-2120.

140. Grabherr MG, Haas BJ, Yassour M, Levin JZ, Thompson DA, Amit I, et al. Trinity: reconstructing a full-length transcriptome without a genome assembly from RNA-Seq data. Nat Biotechnol. 2011;29(7):644-52.

141. Simão FA, Waterhouse RM, loannidis P, Kriventseva E V, Zdobnov EM. BUSCO: assessing genome assembly and annotation completeness with single-copy orthologs. Bioinformatics. 2015;31(19):3210-2.

142. Langmead B, Salzberg SL. Fast gapped-read alignment with Bowtie 2. Vol. 9, Nature methods. 2012. p. 357-9.

143. Li B, Dewey CN. RSEM: accurate transcript quantification from RNA-Seq data with or without a reference genome. BMC Bioinformatics. 2011;12(1):323.

144. Robinson MD, McCarthy DJ, Smyth GK. edgeR: a Bioconductor package for differential expression analysis of digital gene expression data. Bioinformatics. 2009;26(1):139-40.

145. McCarthy DJ, Chen Y, Smyth GK. Differential expression analysis of multifactor RNA-Seq experiments with respect to biological variation. Nucleic Acids Res. 2012;40(10):4288-97. 
146. Altschul SF, Madden TL, Schäffer AA, Zhang J, Zhang Z, Miller W, et al. Gapped BLAST and PSI-BLAST: a new generation of protein database search programs. Nucleic Acids Res. 1997;25(17):3389-402.

147. Boeckmann B, Bairoch A, Apweiler R, Blatter M-C, Estreicher A, Gasteiger E, et al. The SWISS-PROT protein knowledgebase and its supplement TrEMBL in 2003. Nucleic Acids Res. 2003;31(1):365-70.

148. Buchfink B, Xie C, Huson DH. Fast and sensitive protein alignment using DIAMOND. Nat Methods. 2014 Nov 17;12:59.

149. Conesa A, Götz S, García-Gómez JM, Terol J, Talón M, Robles M. Blast2GO: A universal tool for annotation, visualization and analysis in functional genomics research. Bioinformatics. 2005;21(18):3674-3676.

150. Kanehisa M, Goto S. KEGG: kyoto encyclopedia of genes and genomes. Nucleic Acids Res. 2000;28(1):27-30.

\section{Figures}



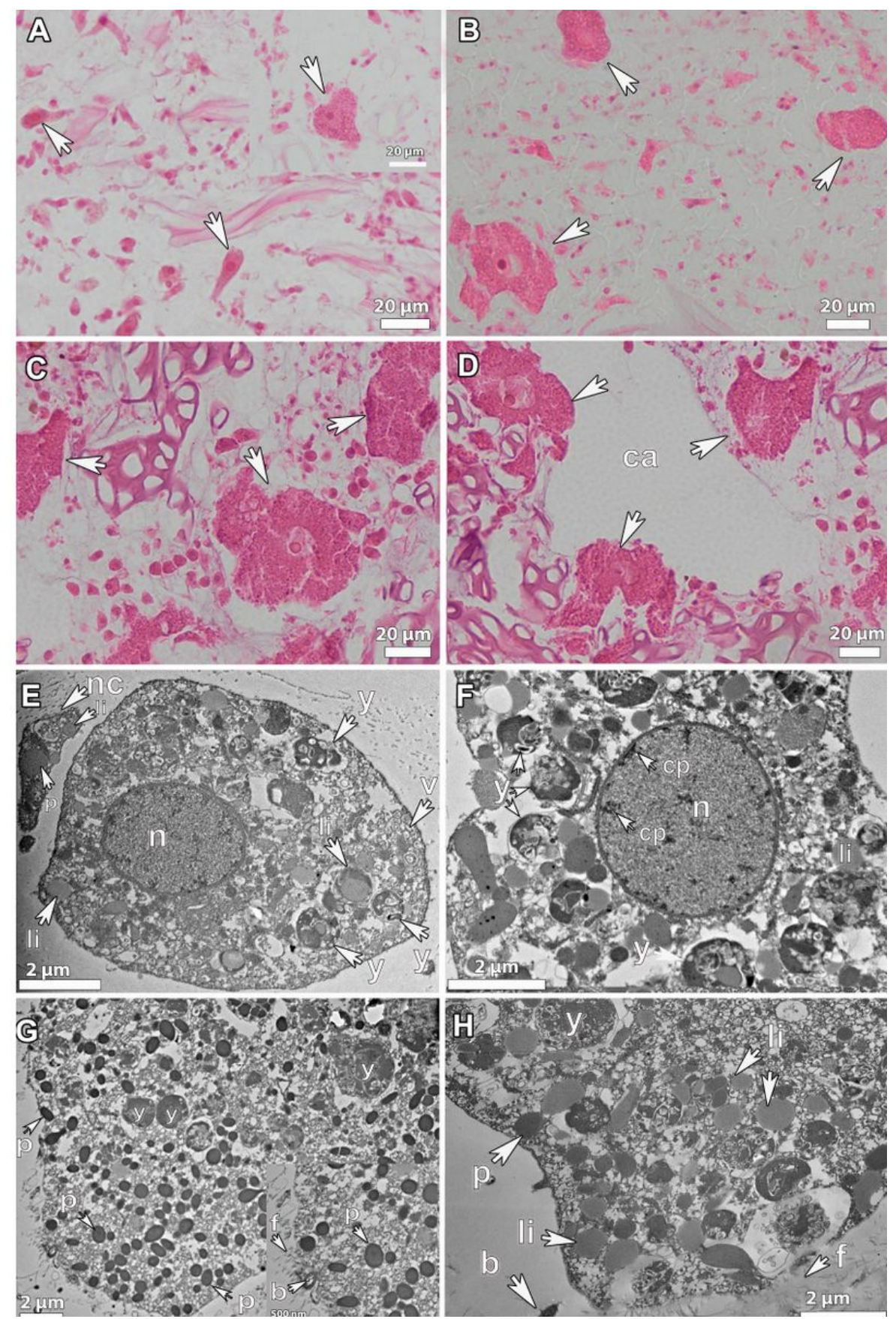

Figure 1

Histological observations of female gametes of Phakellia ventilabrum. A. Previtellogenic oocytes $(\sim 20 \mu \mathrm{m})$ distributed in the mesohyl of a female sponge collected in September in Langenuen, Korsfjord. Insert: a close-up of a previtellogenic oocyte with a well-formed nucleus. B. Oocytes of vitellogenic_stage I (30-40 $\mu \mathrm{m})$ spread throughout the mesohyl of a female sponge collected in September in Skorpeodden, Korsfjord. C. Oocytes of vitellogenic_stage_Il (60-80 $\mu \mathrm{m})$, from a specimen collected in September in Langenuen, Korsfjord. D. Some of the oocytes from the same specimen were accumulated around the canal (ca), to be released in the water column. E. Ultrastructure of a vitellogenic_stage_I oocyte with a well-formed nucleus ( $\mathrm{n}$ ): the ooplasm contains empty vesicles ( $\mathrm{v}$ ) and large droplets of heterogeneous (y) and lipid (li) yolk. In close proximity, a nurse cell (nc) contains protein (p) and lipid (li) yolk. F. A close-up of the ooplasm from an oocyte of vitellogenic stage I. The ooplasm was full of lipid (li) and heterogenous (y) yolk and the nucleus, (n) contained some chromatin compaction (cp). G. Ultrastructure of a vitellogenic_stage_ll oocyte with the ooplasm full of protein ( $p$ ) yolk and few big droplets of heterogeneous yolk (y). Insert: A fibular structure (f) for support and protection of the oocyte 
was formed in the surrounding of the oocyte. Note the phagocytosis of a bacterium (b) from the mesohyl. The ooplasm was full of proteic (p) yolk. H. Ultrastructure of a different vitellogenic stage II oocyte: mesoplasm with plenty of lipid (li) yolk and proteic (p) and heterogenous yolk (y). Oocytes are indicated with white arrows in the images A-D.

\section{Developmental_stage \\ PV: Pre-viłellogenic \\ VI_I: Vitellogenic I \\ VI_II: Vitellogenic II}

A.

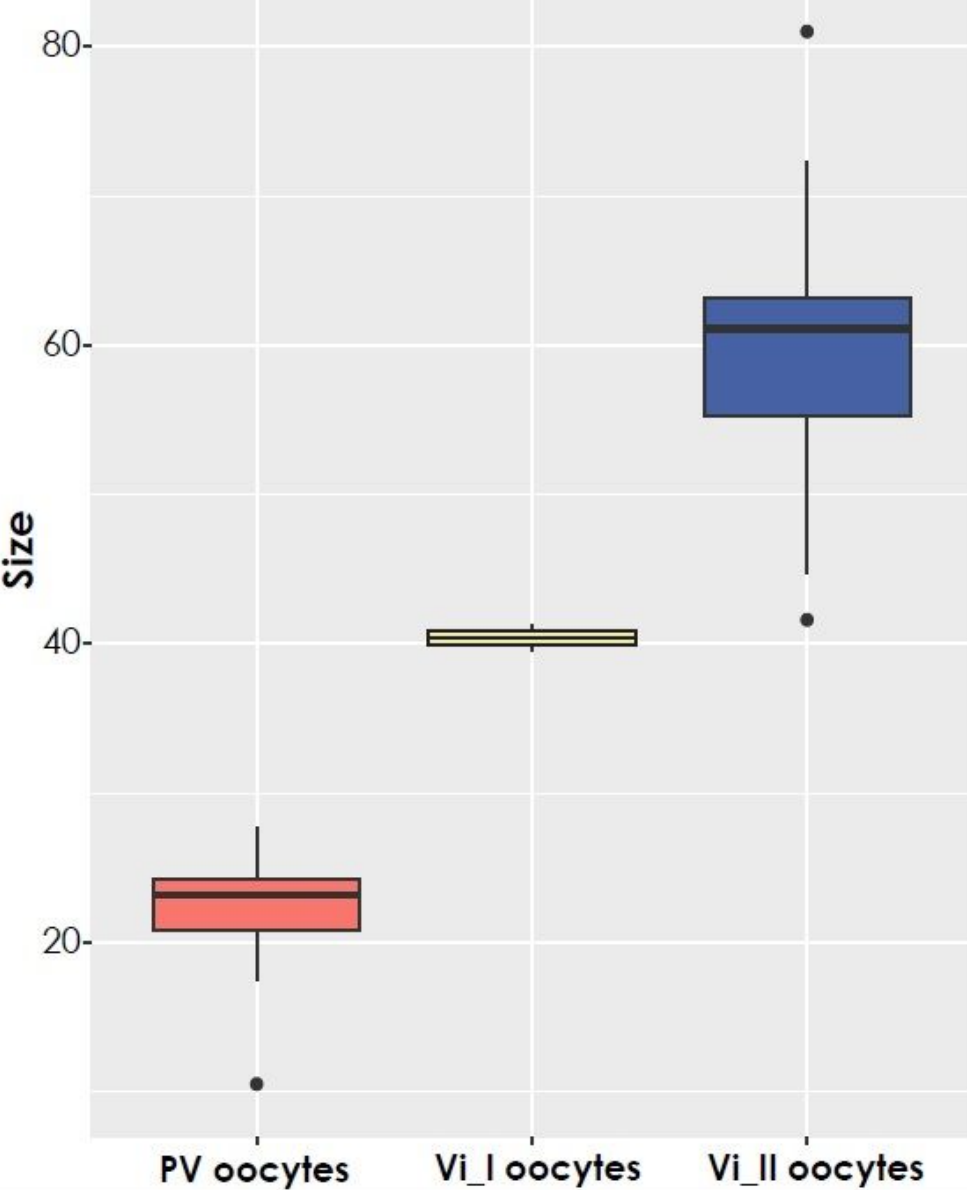

B.

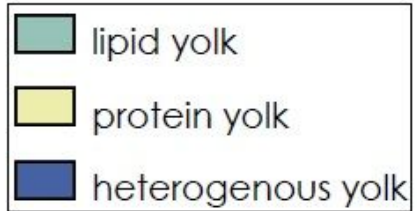

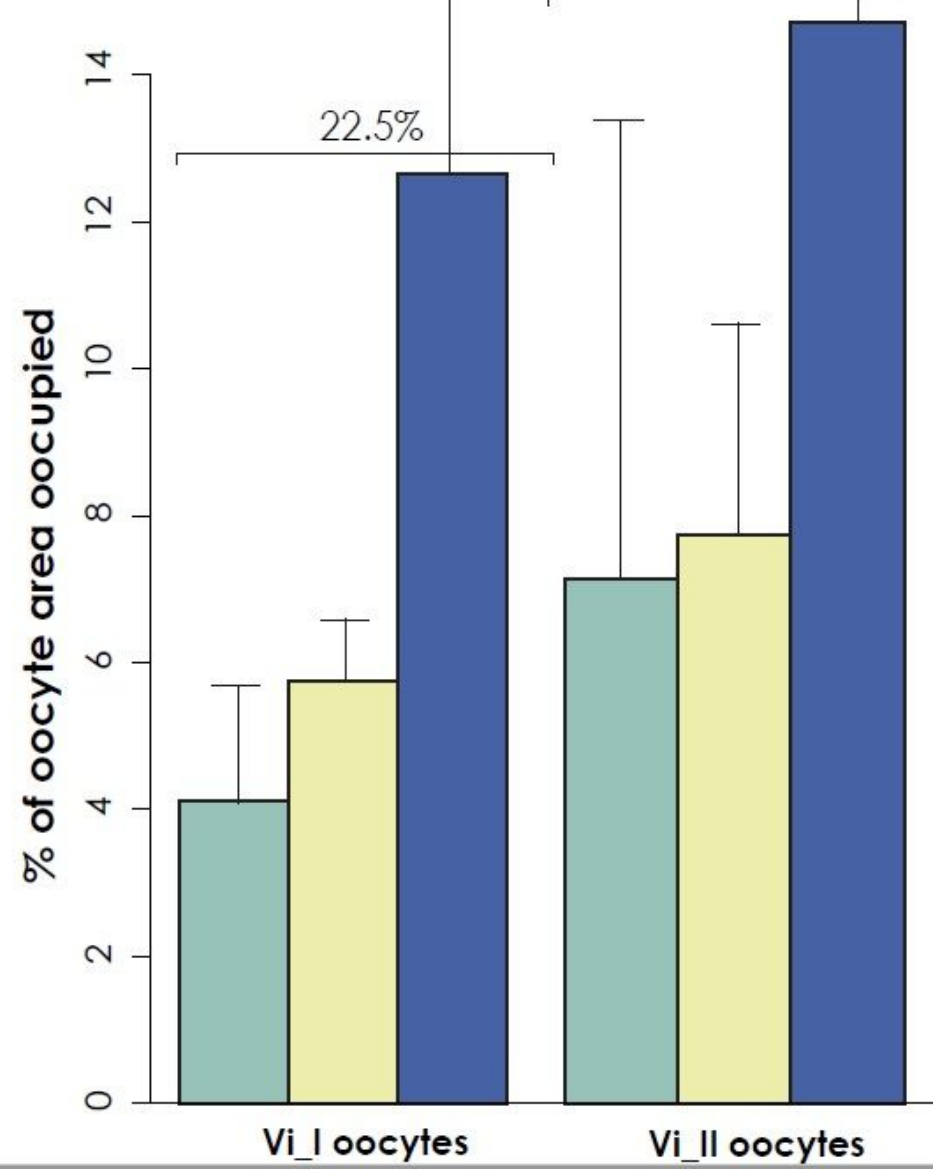

Figure 2

Measurements of oocyte size and yolk content. A. Average size $(\mu \mathrm{m})$ of previtellogenic (PV), vitellogenic_stage I (Vi_I) and vitellogenic_stage II (Vi_II) oocytes. B. Percentage of the oocyte area occupied by the different types of yolk. For these measurements one specimen with vitellogenic stage I oocytes and another specimen with vitellogenic stage II oocytes were used. 


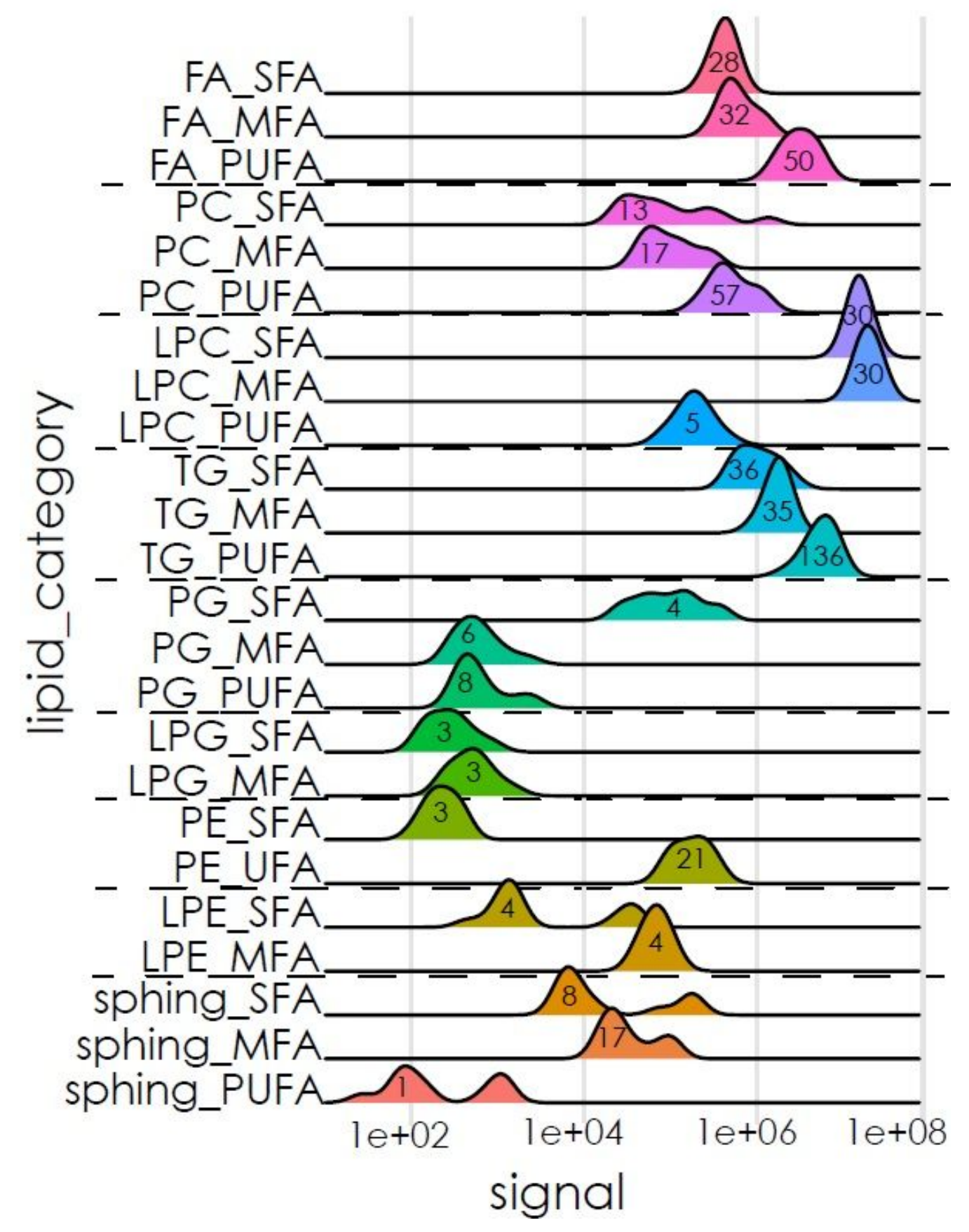

Figure 3

Signal of different lipid categories. The log signal of saturated fatty acids (SFA), monounsaturated fatty acids (MFA), or polyunsaturated fatty acids (PUFA), free fatty acids (FFA), phosphatidylcholines (PC), lysophosphatidylcholines (LPC), triacylglycerides (TG), phosphatidylglycerols (PG), lysophosphatidylglycerols (LPG), phosphatidylethanolamines (PE) and lysophosphatidylethanolamines (LPE), sphingolipids and glycosphingolipids. In each peak the number of detected lipids is indicated. 
A.
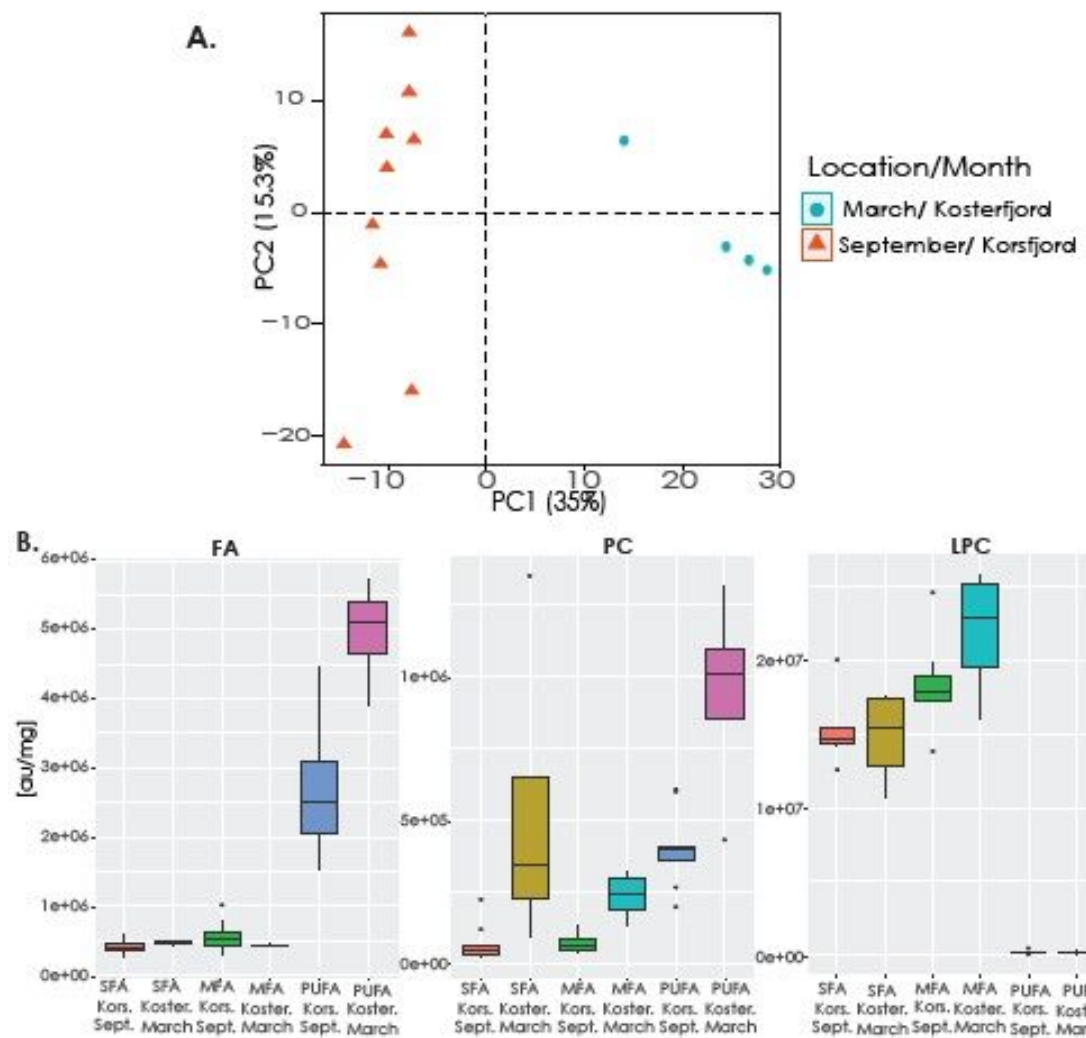

TGs

PC
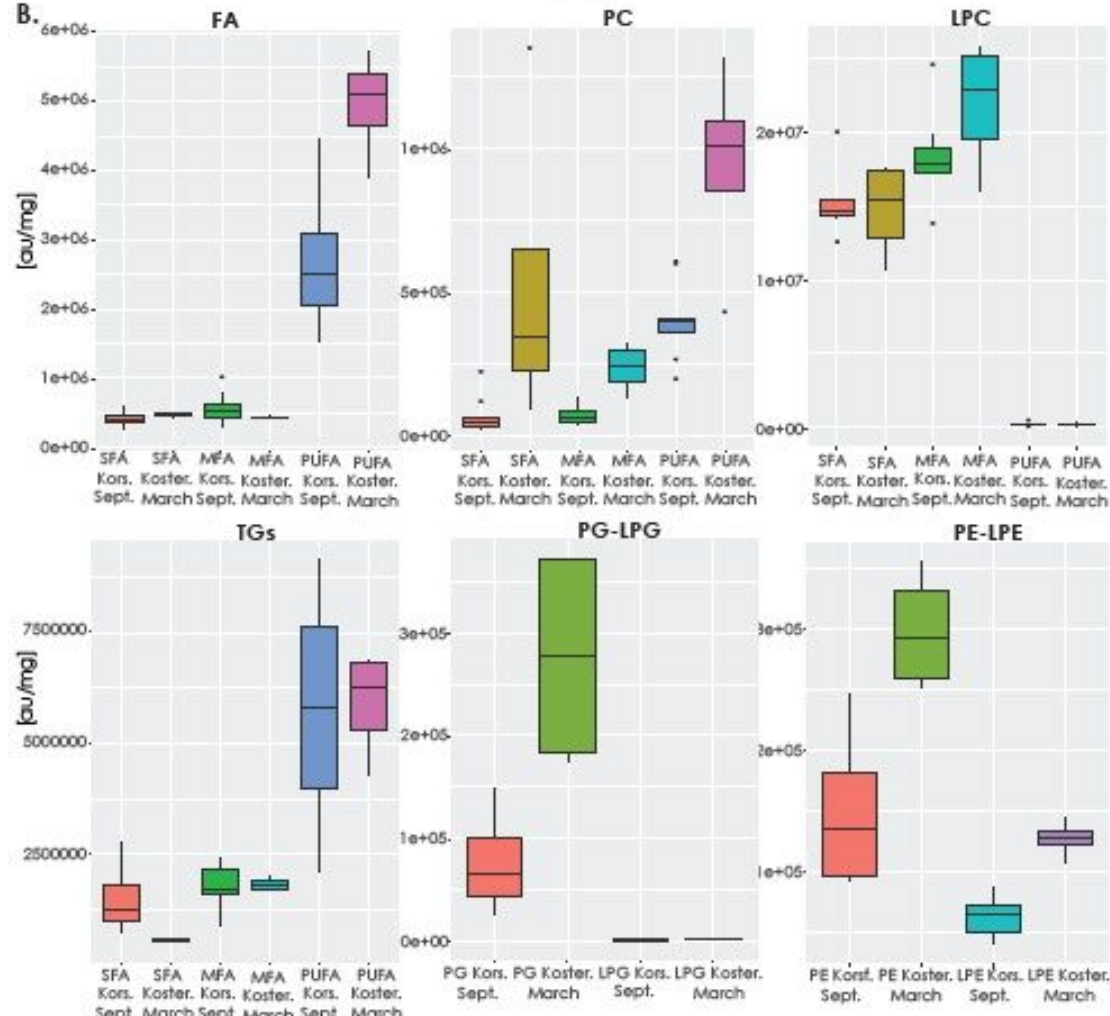

opt. March Kopt. Marar. Kors. Koster.

Sopt. March sept.

(1)

\section{Figure 4}

Lipid signal of different lipid categories in different locations/ months. A. Principal Component Analysis (PCA) indicating the scores of the first two principal components of the lipidome in the sponge individuals between the two different locations. B. Boxplots depicting the average signal [au/mg] extracted from all the lipids of each lipid category in the two different sampling locations/months. Fluctuations in signal [au/mg] were calculated separately for saturated (SFA), monounsaturated (MFA), and poly-unsaturated (PUFA) lipids within each lipid category. Abbreviations: free fatty acids (FFA), phosphatidylcholines (PC), lyso-phosphatidylcholines (LPC), triacylglycerides (TGs), phosphatidylglycerols (PG), lysophosphatidylglycerols (LPG), phosphatidylethanolamines (PE), lyso-phosphatidylethanolamines (LPE), saturated (SFA), mono-unsaturated (MFA), poly-unsaturated (PUFA). 


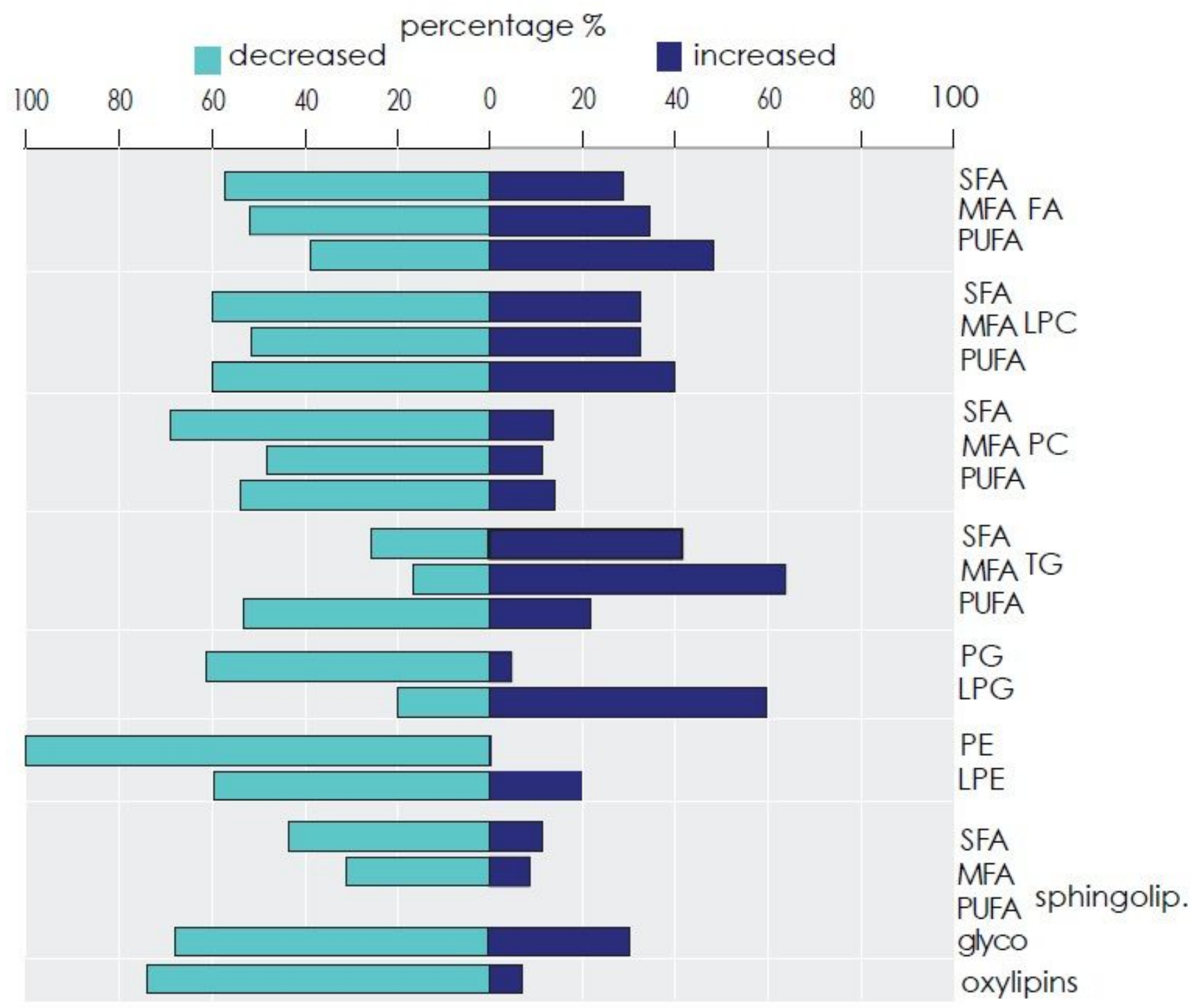

Figure 5

Signal of different lipid cateogires among the different reproductive categories. Barplot presenting the sum of SFA-, MFA-, and PUFA- lipids within each lipid category with a trend of total signal decrease or increase in female, compared to nonreproductive individuals within each lipid category. Abbreviations: free fatty acids (FFA), phosphatidylcholines (PC), lyso-phosphatidylcholines (LPC), triacylglycerides (TGs), phosphatidylglycerols (PG), lyso-phosphatidylglycerols (LPG), phosphatidylethanolamines (PE), lyso-phosphatidylethanolamines (LPE), saturated (SFA), mono-unsaturated (MFA), polyunsaturated (PUFA). 


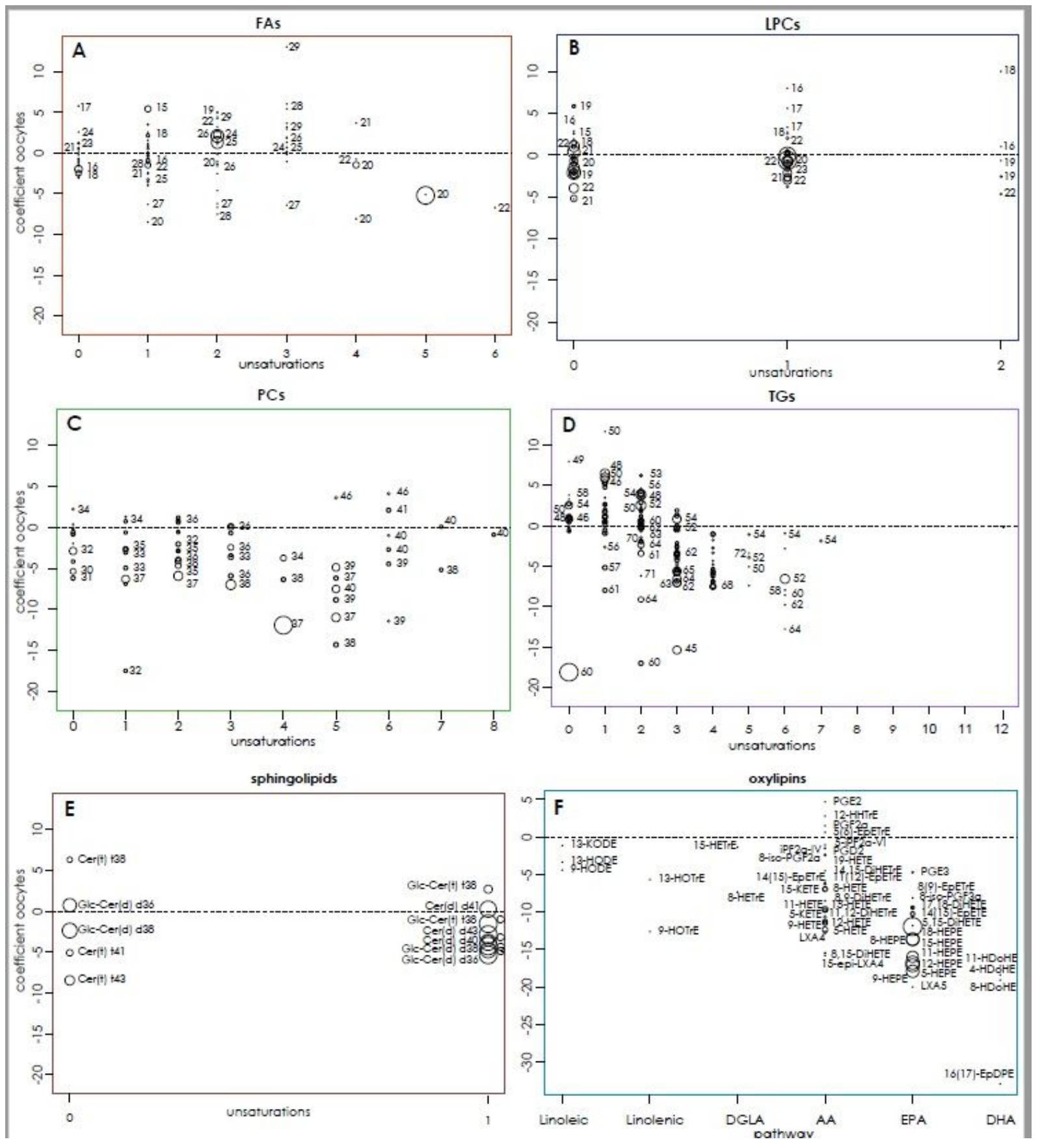

Figure 6

Relationship between lipids and the area of sponge tissue occupied by oocytes for the different lipid categories. A. free fatty acids (FFA); B. lysophosphatidylcholines (LPC); C. phosphatidylcholines (PC); D. triacylglycerides (TGs); E. sphingolipids; F. oxylipins. The $x$-axis represents the number of unsaturations of the lipids and the $y$-axis the coefficient that relates the signal of the lipid with the surface of oocytes. Lipids above the dashed line were upregulated with oocytes, lipids below this line were downregulated with oocytes. To distinguish major from minor species in the same family, the area of the points is proportional to the signal of the lipid in the control group. The number next to the points indicates the number of carbons of the lipid. 


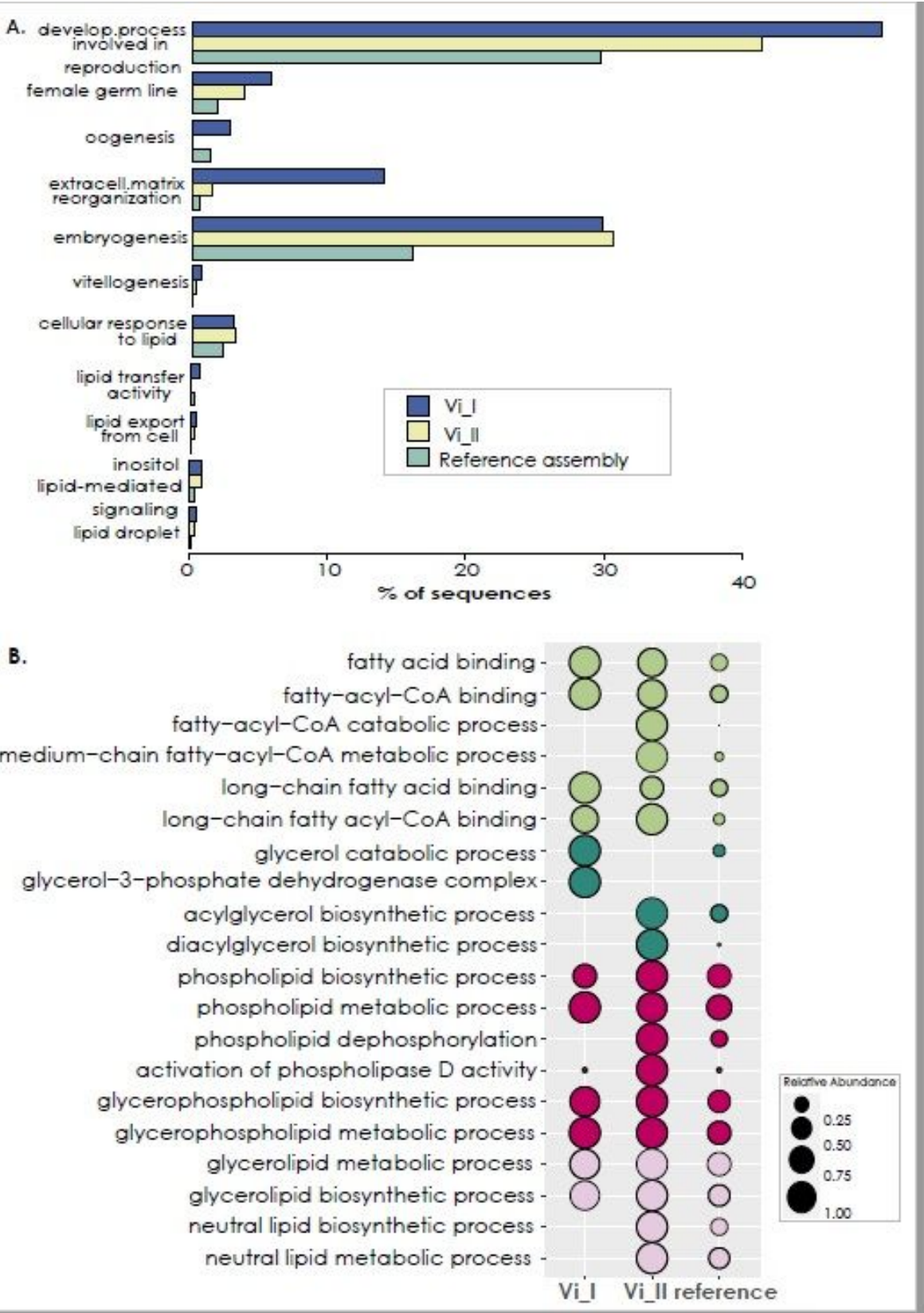

\section{Figure 7}

$\mathrm{GO}$ enriched categories in female specimens. A. Barplot depicting the $\mathrm{GO}$ enriched categories related to oogenesis and female reproduction, based on the upregulated genes in females compared to nonreproductive individuals and the reference transcriptome. B. Bubbleplot presenting GO enriched categories related to lipid metabolism derived from the upregulated genes in females compared to nonreproductive individuals. Each colour represents a different group of categories according to their function and the size of the circle in each case is relative to the expression level of this category. GO enrichment analysis was conducted selecting a p-value $\leq 0.05$. 
A. TG biosynthesis

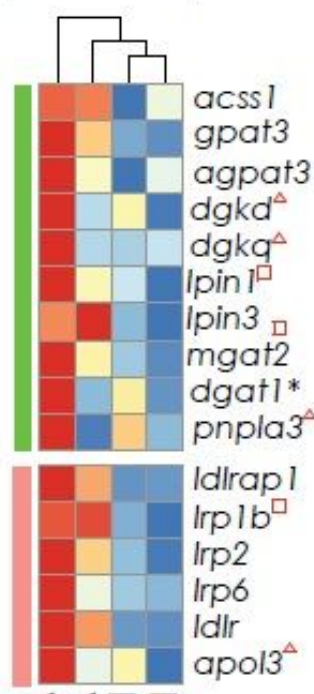

$\leq \leq z Z$
$\leq=1$
B. FA beta-oxidation

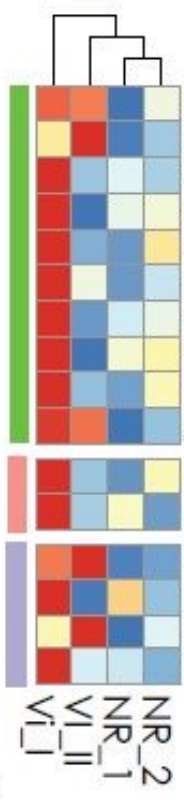

acss 1

cptla

SIc $25 a 20^{\Delta}$

cpt2*

acadll

echsl

hadha $^{\wedge}$

hadh $^{\Delta}$

acaa $^{\wedge}$

ppargcla

elov6 ${ }^{\Delta}$

tecr ${ }^{\Delta}$

$\operatorname{acot7}$ ㅁ

scd

cyb5r ${ }^{\text {प }}$

cyb5 $5 b^{4}$
FA elongation

C.

TG biosynthesis
lipoprotein synthesis

FA beta-oxidation

FA elongation/ UFA Biosynthesis

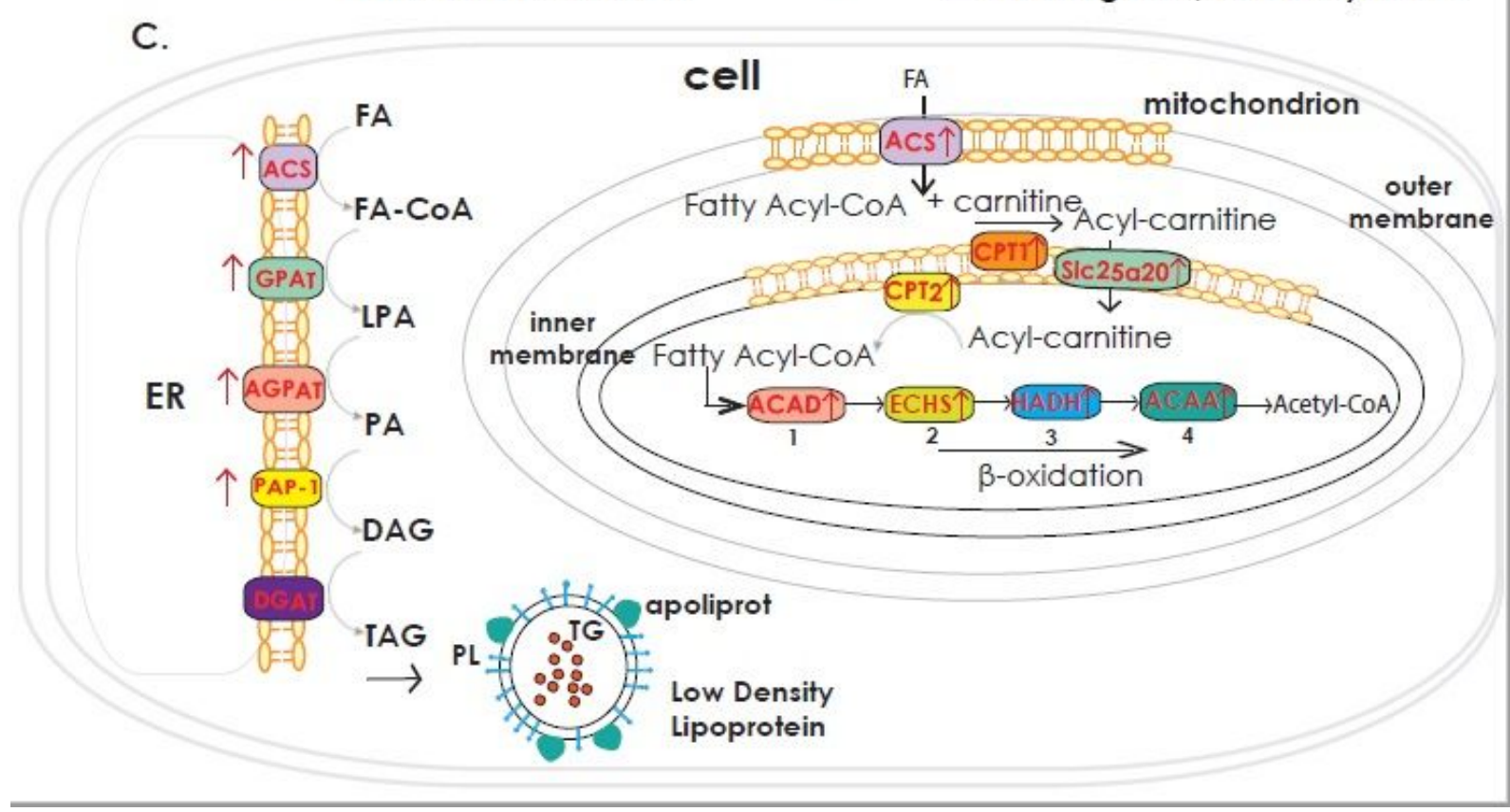

Figure 8

Gene expression patterns of lipid metabolism in P. ventilabrum. A. Heatmap of genes regulating the triacylglyceride (TG) biosynthetic pathway and lipoprotein formation. B. Heatmap of genes regulating the fatty acid (FA) beta-oxidation, FA elongation and synthesis of unsaturated fatty acids (UFA). Relative expression level increases from blue to red. DE genes were overexpressed in females (either vitellogenic I, Vi_l, or vitellogenic II, Vi_II) compared to nonreproductive specimens. The red triangle represents genes that were overexpressed only in Vi_I female while the red square represents genes that were overexpressed only in Vi_ll female. The asterisks show genes that were not overexpressed; however, they were found in the expression matrix and showed a higher expression tendency in females. C. Pathways of triacylglyceride biosynthesis in endoplasmic reticulum (ER), lipoprotein synthesis, fatty acid (FA) beta-oxidation in mitochondria, and the molecular regulators that activate the FA beta-oxidation. The red arrows indicate the overexpression of those genes in female individuals, either or Vi_I or Vi_Il or both stages. 


\section{Supplementary Files}

This is a list of supplementary files associated with this preprint. Click to download.

- Additionalfile1Tables1.xls

- Additionalfile2SF1.pdf

- Additionalfile3Tables2.xlsx

- Additionalfile4Fig.S1.pdf

- Additionalfile5TableS3.xls

- Additionalfile6SF2.pdf

- Additionalfile7TableS4.xls

- Additionalfile8TableS5.xls

- Additionalfile9TableS6.xls

- Additionalfile10TableS7.xlsx

- Additionalfile11Tables8.xlsx

- Additionalfile12Fig.S2.pdf

- Additionalfile13Tables9.xlsx 